\title{
Multiple architectures and mechanisms of latency in metallopeptidase zymogens
}

\author{
Joan L. Arolas ${ }^{\mathrm{a}, 1}$, Theodoros Goulas ${ }^{1}$, Anna Cuppari and F. Xavier Gomis-Rüth *
}

Proteolysis Laboratory; Structural Biology Unit ("María-de-Maeztu" Unit of Excellence); Molecular Biology Institute of Barcelona (CSIC); Barcelona Science Park; c/Baldiri Reixac, 15-21; 08028 Barcelona (Catalonia, Spain).

${ }^{\text {a }}$ Present address: Max F. Perutz Laboratories; University of Vienna; Campus Vienna Biocenter 5; 1030 Vienna (Austria).

* Corresponding author: Tel.:(+34) 934020 186; E-mail: xgrcri@ibmb.csic.es.

${ }^{1}$ These authors contributed equally and share first authorship.

\begin{abstract}
Metallopeptidases cleave polypeptides bound in the active-site cleft of catalytic domains through a general base/acidmechanism. This involves a solvent molecule bound to a catalytic zinc and general regulation of the mechanism through zymogen-based latency. Sixty reported structures from eleven metallopeptidase families reveal that pro-segments, mostly N-terminally of the catalytic domain, block the cleft regardless of their size. Pro-segments may be peptides (5-14 residues), which are only structured within the zymogens, or large moieties $(<227$ residues) of one or two folded domains. While some pro-segments globally shield the catalytic domain through a few contacts, others specifically run across the cleft in the same or opposite direction of a substrate, making numerous interactions. Some pro-segments block the zinc by replacing the solvent with particular side chains, others use terminal $\alpha$-amino or carboxylate groups. Overall, metallopeptidase zymogens employ disparate mechanisms that diverge even within families, which supports that latency is less conserved than catalysis.
\end{abstract}

\section{CONTENTS}

1. Introduction

2. Regulation of Metallopeptidase Activity

3. Synthesis and Activation of Zymogens 4

4. A/B-Type Funnelins 5

5. LytM/Lysostaphin/LasA-Metallopeptidases $\quad 7$

6. Matrix Metalloproteinases 8

7. Astacins 10

8. Fragilysins 11

9. Thuringilysins 12

10. Thermolysins 13

11. Minigluzincins 14

12. Fungalysins 16

13. Anthrax Lethal Factor-type Metallopeptidases 17

14. Aspzincins $\quad 17$

15. Summary and Outlook 19

Author Information $\quad 21$

Corresponding Author $\quad 21$

ORCID 21

$\begin{array}{ll}\text { Notes } & 21\end{array}$

Biographies $\quad 21$

Acknowledgments $\quad 22$

Abbreviations $\quad 22$

References $\quad 25$

\section{INTRODUCTION}

Proteolytic enzymes cleave proteins and peptides by hydrolyzing peptide bonds, and "peptidases" is the general term that encompasses proteases, proteinases and peptide hydrolases ${ }^{1}$. Peptidases are found across the kingdoms of life participating in all major biological processes. They function as indiscriminate degraders during digestion and catabolism of proteins and during tissue turnover associated with wound healing, embryogenic development, menstruation and pregnancy ${ }^{2}$. They also exert fine-tuned regulation through the cleavage of a single or a few bonds, dubbed "limited proteolysis" 2,3. This is a post-translational modification observed during removal of signal peptides; activation or inactivation of enzymes, proteins and bioactive peptides, as found in the blood coagulation and fibrinolysis cascades; cleavage of inactive polyproteins to liberate competent individual domains; assembly of multimeric quaternary structures such as collagen fibers, fibrin clots and viral capsides; and shedding of protein ectodomains from the membrane-bound precursors ${ }^{2,4-8}$. 
Seven chemical classes of peptidases have been described, among them the metallopeptidases (MPs) ${ }^{1}$. These are divided into metalloendopeptidases, which cleave in the middle of peptides, and metalloexopeptidases, which cleave at peptide termini and are divided into aminopeptidases and carboxypeptidases among others. MPs can be mono- or bimetallic, thus binding one or two catalyst metals, which are usually zinc cations. In monometallic MPs, the zinc is mostly tetrahedrally liganded by three atoms from protein side chains and a catalytic solvent molecule at the bottom of an activesite cleft. The solvent is further linked to a general base/acid, which is generally a glutamate. The peptidic substrate is bound in the cleft, so that residue side chains upstream of the scissile bond nestle into non-primed cleft sub-sites $S_{1}, S_{2}, S_{3}$, etc. and those downstream of the bond into primed cleft sub-sites $\mathrm{S}_{1}{ }^{\prime}, \mathrm{S}_{2}{ }^{\prime}, \mathrm{S}_{3}{ }^{\prime}$, etc. ${ }^{9,10}$. In general, $\mathrm{S}_{1}$ ' is the main driver of specificity in MPs ${ }^{10}$. Subsequently, the general base/acid polarizes and poises the solvent for nucleophilic attack on the scissile bond carbonyl, which results in a tetrahedral reaction intermediate and subsequent peptide bond cleavage (see Scheme $1, \mathrm{I}-\mathrm{IV} ;{ }^{11-14}$ ). This mechanism explains why mutants, in which the glutamate is replaced with alanine or glutamine, exhibit only residual activity and, therefore, have often been to prevent autolysis during structural studies (see Table 1).

Scheme 1 - Consensus catalytic mechanism of monometallic MPs. In the unbound enzyme (I), the catalytic metal ion, generally a zinc (grey sphere), binds the catalytic solvent molecule, which is further bound by the general base/acid, mostly a glutamate, in the active site. Upon substrate binding (II), the polarized solvent molecule attacks the carbonyl group of the scissile bond (1), which leads to a tetrahedral reaction intermediate (III). The reaction results in bond breakage and double proton transfer to the newly formed $\alpha$-amino group to give rise to a double-product complex with an upstream (left) and a downstream product (right) (IV), which eventually fall apart to start a new round of catalysis.

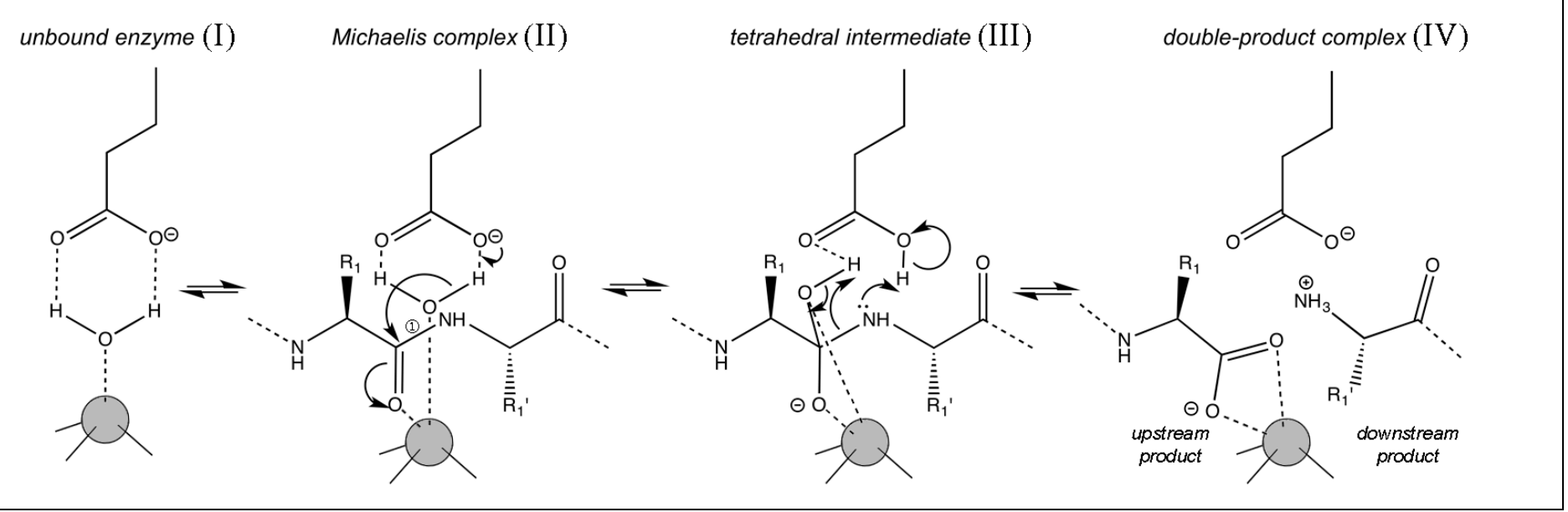

Monometallic MPs include the peptidase tribes of the $\alpha \beta \alpha$-exopeptidases; the LAS MPs (from LytM/lysostaphins, D-alanine-D-alanine MPs and sonic hedgehog, see ${ }^{15,16}$ ); and the zincins, among others (Scheme 2 and ${ }^{13}$ ). The $\alpha \beta \alpha$ exopeptidases encompass the clan of the funnelins, which englobes metallocarboxypeptidases that use a general base/acid glutamate and bind the zinc through a histidine and a glutamate within a short HXXE motif (amino-acid one-letter code;

Scheme 2 - Classification of mononuclear MPs of reported zymogenic structures. Within the MP class of enzymes, mononuclear MPs are a subclass that contains several tribes, including the zincins, LAS MPs and $\alpha \beta \alpha$-exopeptidases. Tribes subdivide into clans and these into families. Catalytic zinc-binding residues are in green, general base/acid residues in magenta, and residues occupying the position of the Met-turn or Ser/Gly-turn beneath the metal site in zincins ${ }^{13}$ are in orange (within gluzincins, $\mathrm{Z}=\mathrm{A} / \mathrm{F} / \mathrm{S} / \mathrm{G} / \mathrm{T}$ ). Other residues engaged in substrate or product binding, stabilization of the reaction intermediate, and/or catalysis are further shown in black. X stands for any residue. MEROPS nomenclature is provided in blue when it matches the groups of the present classification. The clan aspzincins so far contains a single homonymous family. See also ${ }^{13}$ and references therein.

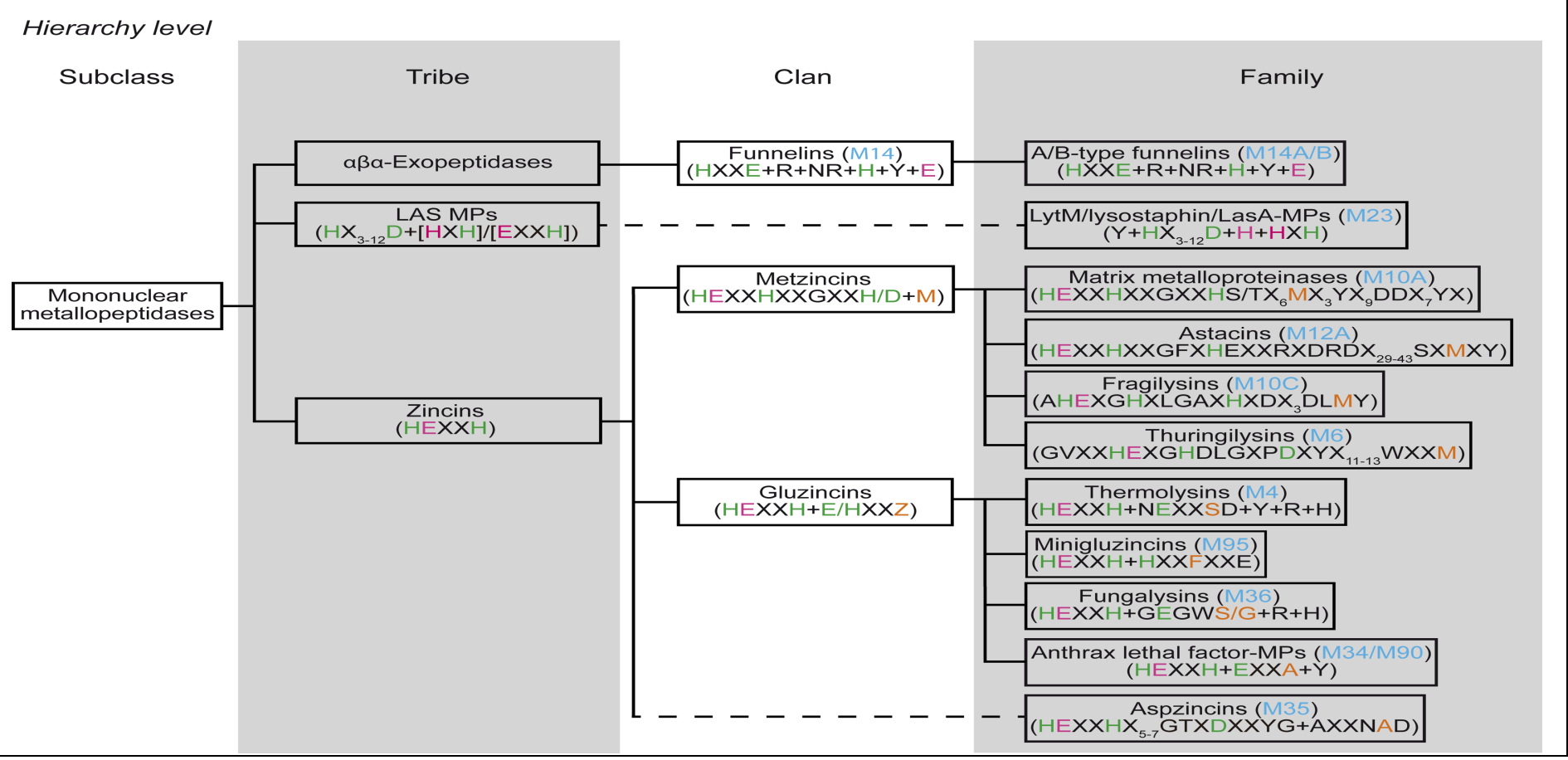


$\mathrm{X}$ stands for any residue) plus a second downstream histidine. LAS MPs bind the zinc through a histidine and an aspartate from one motif $\left(\mathrm{HX}_{3-12} \mathrm{D}\right)$ plus a second histidine from a second downstream motif (EXX $\underline{\mathrm{H}}$ or $\left.\mathrm{HX} \underline{\mathrm{H}}\right)$. In these MPs, the general base/acid is proposed to be either glutamate or histidine from this second motif, although a further histidine may likewise be involved ${ }^{16}$. Finally, zincins contain the short motif HEXXH within an "active-site helix", which encompasses two zinc-binding histidines plus the general base/acid glutamate ${ }^{17}$. Zincins split into three clans: metzincins 13,17-20, gluzincins ${ }^{13,21,22}$ and aspzincins ${ }^{13,23,24}$. These are characterized by respective extended zinc-binding motifs and/or additional downstream motifs, which provide a histidine, glutamate or aspartate as third zinc ligand (Scheme 2).

\section{REGULATION OF METALLOPEPTIDASE ACTIVITY}

Due to the irreversibility of peptide bond cleavage by MPs in vivo-exceptions have been reported in vitro ${ }^{25}$ these enzymes must be exquisitely regulated to prevent aberrant activity, which commonly leads to pathology. Control of MPs is achieved through transcriptional regulation ${ }^{26}$, cellular compartmentalization ${ }^{27}$ and specific or broad-spectrum protein inhibitors ${ }^{28}$, among which multi-domain $\alpha_{2}$-macroglobulins block prey peptidases through pan-peptidase Venusflytrap or snap-trap mechanisms ${ }^{29-32}$. Other inhibitor examples are the tissue inhibitors of metalloproteinases ${ }^{33,34}$; the bacterial bifunctional serine- and metalloproteinase inhibitor sermetstatin ${ }^{35}$; the insect metallopeptidase inhibitor ${ }^{25}$; and several metallocarboxypeptidase inhibitors ${ }^{21,36}$. Some MPs are regulated by the transit between non-functional closed conformations with occluded active sites and competent open conformations through hinge motions. This is the case for cowrins within the $\alpha \beta \alpha$-exopeptidases and other metallocarboxypeptidases ${ }^{21,37}$, which are grouped into the M32 family of the MEROPS database of peptidases and inhibitors (www.ebi.ac.uk/merops, ${ }^{38}$; MP families are characterized by the prefix "M," see Scheme 2 for families described in this study). Insulinase and other inverzincins (M16) behave similarly ${ }^{39}$. An alternative regulatory mechanism is self-compartmentalization into large multimeric hollow particles, which contain the active sites inside, and thus restrict activity to substrates entering through dedicated openings or channels. This is observed in bimetallic zinc MPs such as the tetrahedral dodecameric ApAp-subfamily of archaeal metalloaminopeptidases (M42; ${ }^{40}$ ) and barrel-shaped decameric Bacillus subtilis D-aminopeptidase DppA $\left(\right.$ M55; ${ }^{41}$ ). Finally, MP activity may be regulated through latency exerted by zymogens ${ }^{2,42,43}$.

\section{SYNTHESIS AND ACTIVATION OF ZYMOGENS}

Most MPs are synthesized as inactive or latent zymogens with a pro-segment, which is either a protein domain or a peptide. The pro-segment is removed during activation within the subcellular compartment or the extracellular space in which the mature catalytic domain performs its physiological function ${ }^{2}$. Pro-segments are usually located at the $\mathrm{N}$ terminus of the catalytic domains to prevent activity before the zymogen is fully synthesized, although exceptions are found, e.g. within the minigluzincins (see section 11 and Scheme $2 ;{ }^{44,45}$ ). In general, the catalytic domains are already preformed or in a close-to-competent conformation in the zymogens, so latency is mainly exerted by sterically blocking access of substrates to the active site.

In some instances, the pro-segment is a short peptide, which does not fold independently of the catalytic domain. It only blocks the active site until maturation and is discarded once cleaved. Examples are found in the astacin family $\left(\right.$ section $7 ;{ }^{46}$ ). In other instances, pro-segments are large and fold into separate domains, which once cleaved may still inhibit their cognate MPs in trans. They often also contribute to folding, thus chaperoning the downstream mature catalytic domain, to stability and intracellular sorting of the zymogen and to binding of other proteins ${ }^{4,42,47-51}$. Examples of such large pro-segments include funnelin metallocarboxypeptidases (section 4; ${ }^{50,52,53}$ ); LytM/lysostaphin/LasA-MPs (section $5 ;{ }^{54}$ ) within LAS MPs; several metzincin families, e.g. the adamalysins/ADAMs (M12B; ${ }^{55}$ ), matrix metalloproteinases (MMPs; section 6; ${ }^{56}$ ), fragilysins (section $8 ;{ }^{57}$ ) and thuringilysins (section 9; ${ }^{58}$ ); thermolysins (section $10 ;{ }^{59}$ ) and fungalysins (section 12; ${ }^{60}$ ) within gluzincins (Scheme 2); and aspzincins (section 14; ${ }^{24}$ ).

Pro-segment removal occurs through single- or multi-step limited proteolysis, which may be autocatalytic and triggered by external reagents, changes in $\mathrm{pH}$ or simple incubation at high concentration ${ }^{61,62}$. Pro-segment cleavage can also be heterolytic through other peptidases, as described for pro-MMPs ${ }^{63}$. Some zymogens are activated through association with proteins, which induce allosteric changes that liberate activity without removal of the pro-segment. Examples include pro-MMP-2 and pro-MMP-9 ${ }^{64-66}$, as well as members of the anthrax lethal factor-type MPs (section 13). A case apart is selecase, a minimal MP that exhibits reversible concentration-dependent latency (section $11 ;{ }^{44}$ ). Yet other zymogens - such as those of some MMPs — are activated by chemicals that react with pro-segment residues and thus release the active-site cleft without pro-segment cleavage ${ }^{67}$.

Currently, three-dimensional structures of MP zymogens or zymogenic complexes are available for monometallic enzymes only, and the structural determinants of their mechanisms of latency are discussed hereafter (see also Schemes 2 and 3 plus Table 1).

\section{A/B-TYPE FUNNELINS}

Funnelins - alias M14 metallocarboxypeptidases_include the A/B-type (M14A) and E/D-type (M14B) members, which are mainly extracellular enzymes from animals $21,36,50,52,68,69$. They are engaged in the digestion of proteins and peptides but also in pro-hormone and neuropeptide processing and in several other roles in different mammalian extrapancreatic tissues and fluids ${ }^{69}$. One protein was reported from the bacterium Lysinibacillus sphaericus, which is involved in the metabolism of the bacterial cell wall (M14C). More recently, the intracellular cytosolic carboxypeptidases (M14D) were discovered in mammals and classified into a distinct group ${ }^{70,71}$. Porcine pancreatic pro-carboxypeptidase B1 was the 
first MP, for which the zymogen structure was solved in $1991^{72}$, and to date sixteen more pro-funnelin structures have been published, all from A/B-type zymogens (Table 1). As to the cytosolic carboxypeptidases, the structure of an inactive potential orthologue from Pseudomonas aeruginosa was reported ${ }^{73}$, which likely is an active form whose substrate has not yet been determined, rather than a zymogen.

As exemplified by prototypic human pro-carboxypeptidase $\mathrm{A} 4{ }^{74}$, A/B-type zymogens consist of highly similar $\sim 310$-residue catalytic domains of $\alpha_{8} / \beta_{8}$ topology and $\alpha / \beta$-hydrolase fold (Scheme $3 \mathrm{~A} ;{ }^{75,76}$ ). Framed by loops connecting the core helices and strands, these domains have a compact globular shape and a funnel-like opening, at whose base the active-site cleft resides ${ }^{21}$. The catalytic domains, which are already in an active conformation in the zymogen, are preceded by an N-terminal pro-segment of 90-95 residues, which inhibits the cognate mature catalytic domain in trans in several family members $50,52,53$. The pro-segment consists of an $\sim 80$-residue globular part and a C-terminal mostly helical connecting segment. Zymogen activation occurs stepwise through limited proteolysis at the end of this segment in a region that is $\alpha$-helical in A-type zymogens, but not in B-type. As peptidases normally cleave substrates in extended conformation ${ }^{77}$, this entails that the polypeptide must unwind before the cut. After cleavage, the pro-segment is released and degraded in vivo.

Scheme 3 - Structures of prototypic MP zymogens (I). Normally, MP structures are best displayed following the established standard orientation, which provides a frontal view of the horizontally-aligned active-site cleft ${ }^{10}$. However, given that pro-segments block the cleft mostly frontally, specific orientations for each zymogen were chosen here and in Schemes 4 and 5 to provide the best view into the distinct latency mechanisms. The pro-segments are shown in sandy brown, the catalytic domains in aquamarine, the catalytic zincs as magenta spheres, the zinc-binding residues and the general base/acid residues as yellow sticks, and selected relevant pro-segment and catalytic-domain residues as red sticks. The $\mathrm{N}$ - and C-termini of the zymogens are labelled. Non-catalytic structural calcium and zinc ions are depicted as dark red and magenta spheres, respectively, within catalytic domains only for clarity. Flexible segments connecting the prosegments with the catalytic domains are pinpointed by dotted lines. For PDB access codes of the structures and references, see Table 1. (A) Human pro-carboxypeptidase A4. (B) Klebsiella pneumoniae pro-MtfA. (C) Staphylococcus aureus proLytM. (D) Helicobacter pylori pro-Csd3. The catalytic domain is inserted into an intermediate domain (in white) downstream of the pro-segment. (E) Human pro-MMP-2. The three fibronectin-type-II domains inserted within the catalytic domain are shown in white. (F) Tannerella forsythia pro-karilysin.

A

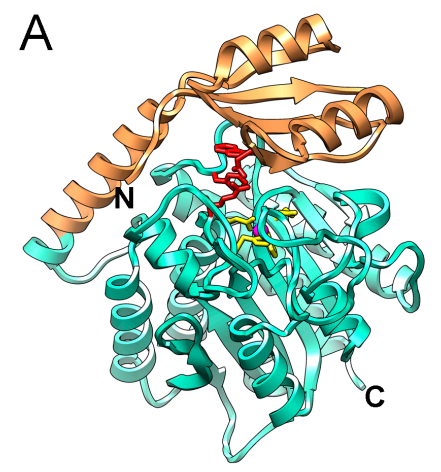

C

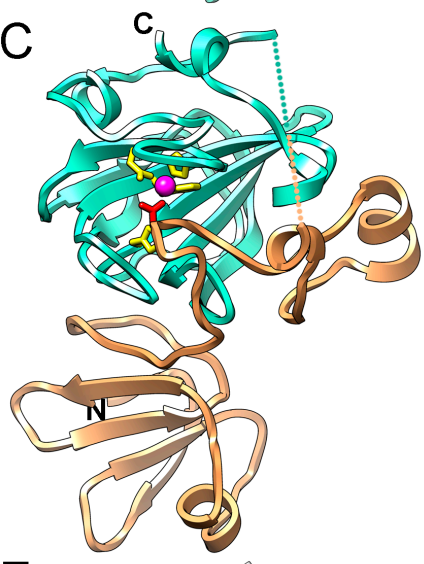

E

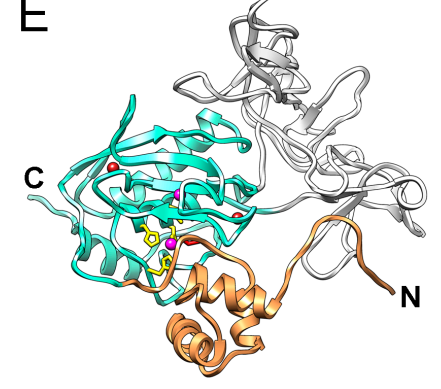

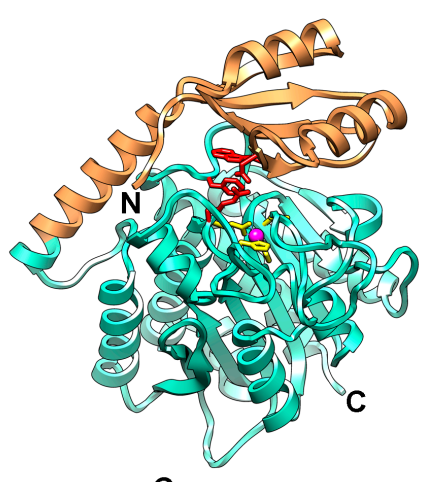

c
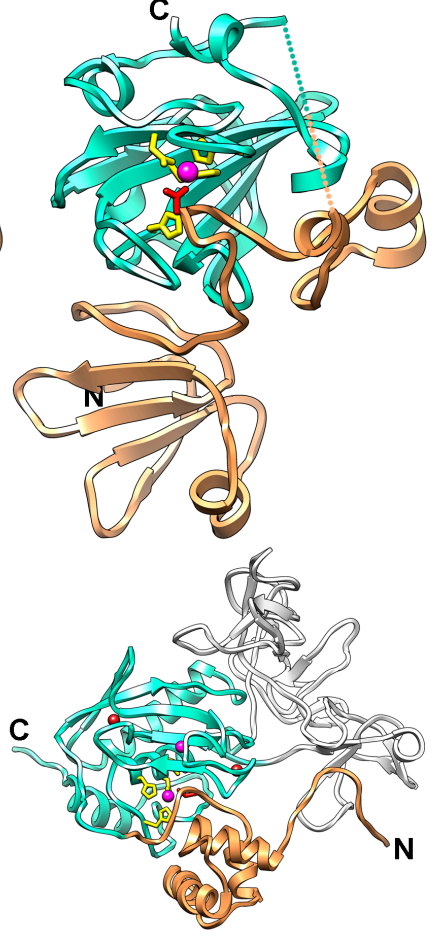

$\mathrm{B}$

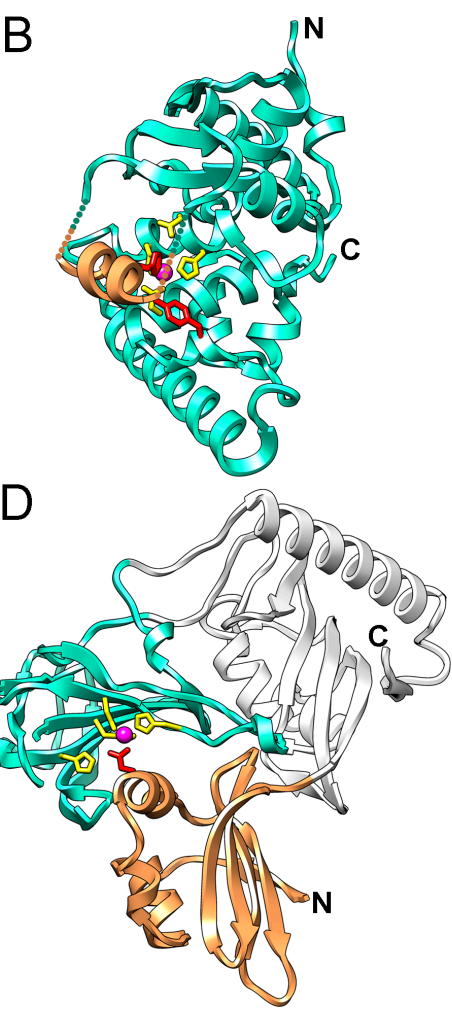

F

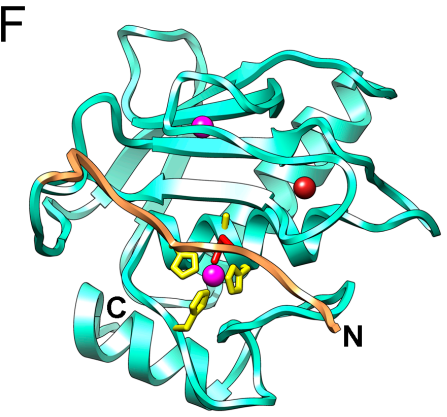

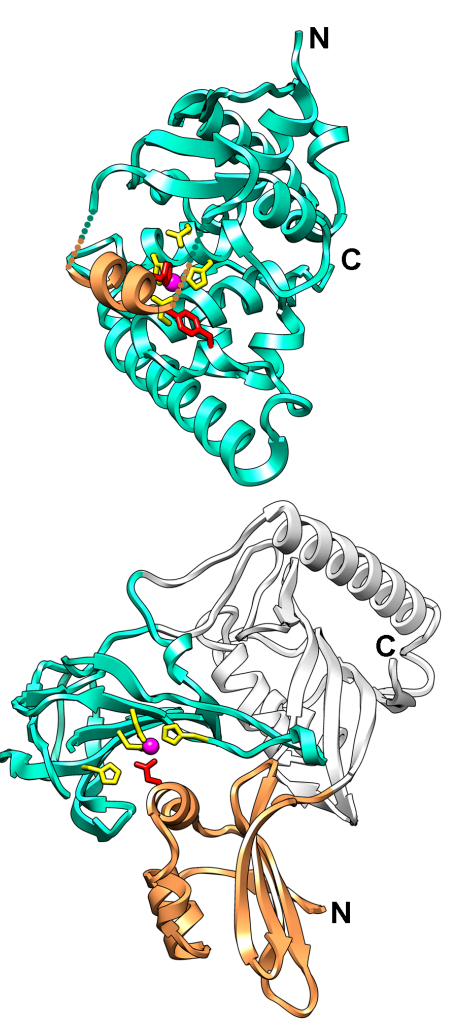

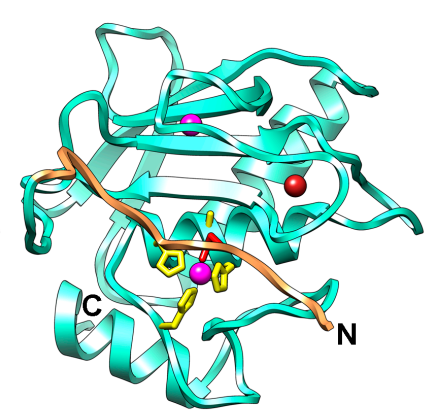

The globular part of the pro-segment is an open-sandwich with a twisted four-stranded antiparallel $\beta$-sheet, packed through its face distal to the enzyme against two nearly parallel $\alpha$-helices. These are inserted between the first two and the last two strands, respectively, and their axes roughly parallel the sheet $\beta$-strands. The pro-segment covers, but not completely shields, the catalytic domain through a large interface, which is created by a $\beta$-ribbon from the pro-segment made up of the second and third sheet strands and by catalytic-domain funnel-rim loops. The pro-segment prevents 
substrate access but does not approach the active site, and only few direct contacts are made with the catalytic domain ${ }^{74}$. These include a conserved electrostatic interaction between a pro-segment aspartate/asparagine and an active-site proximal arginine, and hydrophobic contact of a pro-segment tryptophan with a catalytic-domain phenylalanine/tyrosine (Scheme 3A). Most B-type zymogens contain an additional salt bridge between a pro-segment aspartate and a catalytic-domain arginine. This contributes to a tighter inhibitory complex and explains why B-type zymogens are inert, while A-type zymogens have residual activity in front of small substrates ${ }^{69}$. All these interactions are missing in what is probably the physiologically most relevant A/B-type metallocarboxypeptidase due to its key role in blood coagulation, viz. thrombin activatable fibrinolysis inhibitor. This explains why this zymogen is active even against larger peptides ${ }^{78,79}$.

\section{LYTM/LYSOSTAPHIN/LASA-METALLOPEPTIDASES}

LAS enzymes (families M15 and M23) are a disparate group of peptidases engaged in turnover of the bacterial cell envelope ${ }^{15}$. Their catalytic domains contain a four-stranded antiparallel $\beta$-sheet of conserved topology and connectivity, which provides the zinc ligands, within otherwise diverging overall architectures (Scheme 3C,D). Within these enzymes, extracellular Staphylococcus aureus LytM is a representative of the LytM/lysostaphin/LasA-MPs found in bacteriophages, both Gram-positive and Gram-negative bacteria, and the malaria mosquito, Anopheles gambiae ${ }^{54}$. In addition to LytM 16, structurally-characterized mature proteins include Staphylococcus simulans lysostaphin ${ }^{80}$, Pseudomonas aeruginosa LasA $^{81}$ and Escherichia coli MepA ${ }^{82}$.

The structure of prototypic pro-LytM ${ }^{54}$ reveals an N-terminal pro-segment of $\sim 160$ residues connected through a flexible C-terminal segment with the already preformed $\sim 130$-residue catalytic domain. The pro-segment consists of a core with a four-stranded antiparallel $\beta$-sheet plus a short helix, which is loosely attached to the catalytic domain far from the active-site cleft, and a second small bihelical core. These two moieties are connected by a coiled segment that enters the active-site cleft, so that asparagine $\mathrm{N}^{117}$ blocks activity by binding the catalytic zinc in replacement of the catalytic solvent (Scheme 3C). Consistently, removal of the pro-segment yielded activity in vitro ${ }^{54}$. This latency mechanism was termed the "asparagine switch" 54 by analogy with the "cysteine switch" of MMPs (see section 6).

Due to the poor conservation of the asparagine in LytM/lysostaphin/LasA-MPs, diverse residues likely take over its role in other family members, so that the latency mechanism would rather correspond to a "zinc-ligand switch" 54. Indeed, Helicobacter pylori Csd3, which shares the catalytic domain core with LytM, has a different $\sim 95$-residue prosegment with a five-stranded antiparallel $\beta$-sheet and three short $\alpha$-helices inserted between the first two strands plus an extra $\sim 100$-residue downstream domain, into which the catalytic domain is inserted (Scheme 3D and Table 1). Here, the pro-segment provides the scaffold for a zinc-blocking glutamate $\left(\mathrm{E}^{74}\right)$ inserted within the third helix ${ }^{83}$. A similar threedomain architecture to Csd3 was found in proteins NMB0315 from Neisseria meningitides ${ }^{84}$ and VC0503 from Vibrio cholera $^{85}$, in which segments coming from an N-terminal domain likewise enter the active-site cleft. However, they do not disturb the zinc coordination sphere, which is potentially functional. Thus, these two forms could be zymogens ${ }^{83}$, but also active enzymes with short-substrate specificities or exopeptidase activity. Finally, large variability among LytM/lysostaphins/LasA-MPs further implies that not even zymogenicity is conserved: some members lack a pro-segment and are active as full-length proteins, as shown for Staphylococcus aureus $\mathrm{LytU}^{86}$.

\section{MATRIX METALLOPROTEINASES}

The zymogens of the MMP family were the first to be structurally analyzed within the metzincin clan of MPs (Table $1 ;{ }^{87}$ ). MMPs are mostly secreted enzymes and broadly process extracellular matrix components, but they also shed membrane-bound substrates and activate other peptidases through limited proteolysis ${ }^{8,88}$. They are involved in chronic inflammatory diseases and degrade basement membrane components during several pathologies, including cancer and metastasis processes ${ }^{7}$. There are $23 \mathrm{MMP}$ paralogs in humans, which mostly consist of several modules: an $\sim 80$-residue pro-segment; a $\sim 165$-residue zinc- and calcium-dependent catalytic domain; a linker region; a $\sim 200$-residue hemopexinlike domain with binding functions; and other C-terminal domains ${ }^{87}$. Human MMPs are kept latent through a pro-segment, which is generally not required for (re)folding of the downstream catalytic domain ${ }^{89}$.

To date, sixteen zymogen structures have been reported for human MMP-1, -2, -3, -7 and -9, and bacterial karilysin from Tannerella forsythia, an oral-microbiome member of several animal hosts (Table 1). By comparison with mature forms, the human zymogen structures reveal that the catalytic domains are already in competent conformations in the zymogens ${ }^{87}$. Like other metzincins catalytic domains, which generally span 132-309 residues ${ }^{13,18,58,90}$, MMPs consist of an upper and a lower sub-domain separated by a central active-site cleft. The upper sub-domain contains a "backing helix", an active-site helix, and a mostly five-stranded $\beta$-sheet, in which all strands except the lowermost are parallel to a substrate bound in the cleft. The latter strand is antiparallel, forms the cleft's "upper rim" and binds substrates through $\beta$-ribbon-like interactions between the respective main chains. The lower sub-domain includes a conserved methionine-containing "Metturn" immediately beneath the catalytic cation and a "C-terminal helix" (see Scheme 3E,F and ${ }^{87}$ ). Uniquely, the catalytic domains of MMP-2 and MMP-9 have three fibronectin type-II-related domains inserted between the fourth strand of the $\beta$-sheet and the active-site helix (Scheme 3E). The latter helix and the downstream segment, which leads to the interface between the sub-domains, contain the residues of the extended zinc-binding sequence characteristic for metzincins, HEXXHXXGXXH/D (Scheme 2). The architecture of human MMP catalytic domains is shared with that of bacterial karilysin (Scheme 3F), which is probably the result of horizontal gene transfer from an animal host to T. forsythia ${ }^{91}$.

Structurally characterized MMP pro-segments from mammals comprise 66-91 residues ${ }^{87}$ and frontally shield the active-site clefts. As exemplified by pro-MMP-2 (Scheme 3E; ${ }^{92}$ ), the 80 -residue pro-segment has an extended N-terminus that is initially flexible and thereafter interacts with the third fibronectin-type-II insertion of the catalytic domain before shaping a globular moiety. This moiety has a hydrophobic core made up by side chains from a three-helix bundle, which 
forms a scaffold to place the downstream segment in extended conformation to block the active-site cleft. This peptide encompasses a conserved cysteine-switch or "velcro" motif" (PRCGXPD, ${ }^{93-95}$ ), and runs in the opposite direction to a substrate, so that it cannot produce a productive Michaelis complex. Thus, this is a strategy to prevent autolytic cleavage of the pro-segment ${ }^{42}$ and it is found also in other MPs (see the sections below). The cysteine of the motif binds the catalytic zinc ion via its $\mathrm{S} \gamma$ atom, thus replacing the catalytic solvent molecule and yielding the zymogen inactive. A further key element of the pro-segment structure is an invariant salt bridge between the arginine and the aspartate of the motif. Exceptionally, this element is absent from the motif of pro-MMP-26 (PHCGXXD), which is thus not functional and apparently not involved in the activation mechanisms of this MMP ${ }^{96}$.

Scheme 4 - Structures of prototypic MP zymogens (II). (A) Enterotoxigenic Bacteroides fragilis pro-fragilysin-3. (B) Astacus astacus pro-astacin. (C) Bacillus anthracis pro-BaInhA2, with the inserted VEG and MAM domains in white and in gray, respectively. (D) Serratia proteamaculans pro-protealysin. (E) Pseudoalteromonas sp. vibriolysin in complex with its pro-segment in an orientation of its catalytic domain similar to pro-protealysin in (D). The C-terminus of the prosegment and the N-terminus of the catalytic domain are pinpointed by blue and purple arrows, respectively. Protein domains and features are rendered and colored as described in the legend of Scheme 3.
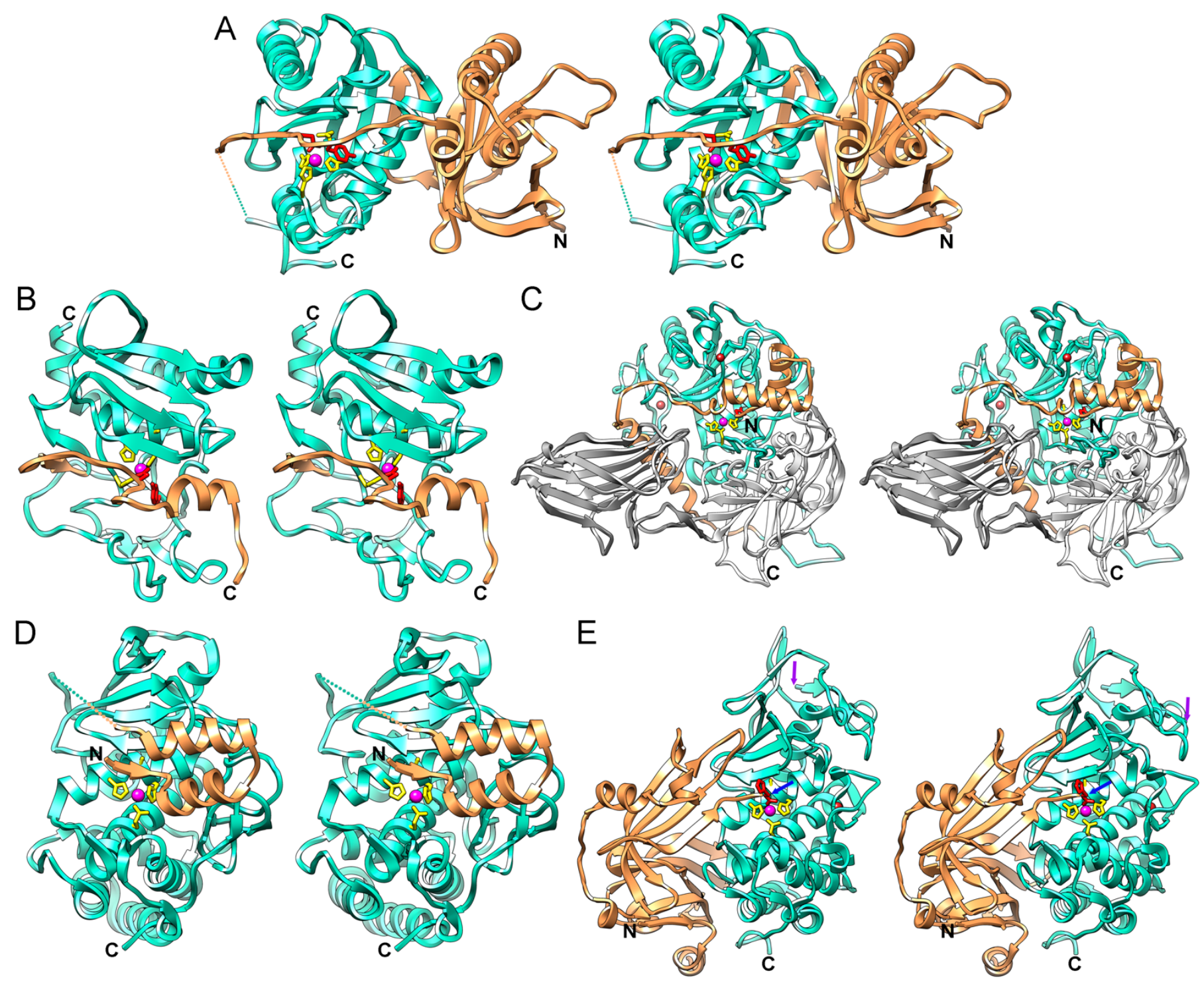

Activation of pro-MMPs is produced in vitro through chemicals that pull out the cysteine from the active-site cleft and give rise to a functional catalytic solvent-zinc pair, but this does not remove the pro-segment. Pro-segment removal is observed during activation through multistep limited proteolysis by trypsin, plasmin, and other MMPs ${ }^{97}$, for example. Depending on the final activation cleavage reaction, mature MMP catalytic domains have different N-termini. Variants that are most stable and physiologically relevant are obtained by cleavage of an X-F/Y bond $\left(\mathrm{N}^{109}-\mathrm{Y}^{110}\right.$ in MMP-2), because they can make a salt-bridge between the new N-terminus and an aspartate from the C-terminal helix ${ }^{87}$. Other MMPs such as the membrane-type variants possess a specific recognition sequence for activation through Golgi-associated Kex2/furin-like convertases.

Although the cysteine-switch mechanism was derived from mammalian MMPs, sequence analyses revealed that plant MMPs likely also contain a pro-segment with a cysteine-switch motif, which, however, may occasionally diverge from the consensus ${ }^{98,99}$. Accordingly, this mechanism of latency seems to be widely conserved across eukaryotic MMPs ${ }^{99}$. Furthermore, the more distantly related members of the gametolysin family of MPs from green algae, such as unicellular Chlamydomonas reinhardtii and multicellular Volvox carteri, may likewise operate through a cysteine switch ${ }^{99-102}$. Finally, similar mechanisms may also occur in other metzincin families with conserved cysteine-containing motifs in their prosegments, such as the ADAMs/adamalysin (motif PKMCGV), leishmanolysin (motif HRCIHD) and pappalysin families (motif CG) ${ }^{87,103-106}$. 
A different architecture and, thus, mechanism within MMPs has been described for T. forsythia pro-karilysin. This 472-residue protein just contains a 14-residue pro-segment- the shortest N-terminal pro-segment for a structurally analyzed pro-MP — without cysteines upstream of a 161-residue MMP-type catalytic domain and a further 277-residue Cterminal extension unrelated to any domain of eukaryotic MMPs. Latency is exerted by the pro-segment running in an extended conformation across the cleft in the opposite direction to a substrate and acting through an "aspartate-switch" mechanism — first described for astacins (section 7; ${ }^{107}$ ) — in which aspartate $\mathrm{D}^{25}$ replaces the cysteine of mammalian MMPs and binds the zinc in a monodentate manner (Scheme 3F).

\section{ASTACINS}

This family encompasses secreted or membrane-bound multi-domain MPs with manifold biological functions across animals. Among others, they are involved in digestion, developmental processes, tissue differentiation and embryonic hatching ${ }^{46}$. The family's eponym is the digestive enzyme astacin from the European freshwater crayfish Astacus astacus ${ }^{46,108}$. Astacins include pro-segments of variable length (from 34 residues in astacin to 483 residues in Drosophila melanogaster tolkin), 200-residue catalytic domains with overall metzincin architecture (see section 6) that are crosslinked by two or three disulfide bonds, and further downstream extracellular domains, trans-membrane anchors, and cytosolic domains ${ }^{46}$.

The pro-segment of pro-astacin, which does not have an intramolecular chaperone function ${ }^{46}$, contains an aspartate embedded in a conserved motif, FE/QGDI, which acts as an aspartate switch ${ }^{107}$. To prevent premature autolysis, the pro-segment both runs along the active-site cleft in the opposite direction to a substrate (see also section 6) and adopts a non-cleavable helical conformation on the primed side of the cleft (Scheme 4B). Thereafter, the chain forms a large loop protruding from the surface. This gives rise to a small globular nucleus that poises the aspartate of the pro-segment motif $\left(\mathrm{D}^{21 \mathrm{P}} ;{ }^{107}\right)$ to occupy the position of the catalytic solvent and bidentately bind the catalytic zinc through its side chain. The loop structure is further stabilized by an electrostatic interaction between the glutamate/glutamine of the pro-segment motif and the penultimate residue of the pro-segment, an arginine. The pro-segment runs in extended conformation along the cleft after the aspartate and binds the upper-rim strand. Thereafter, a short $\beta$-hairpin includes the final maturation cleavage point, which is buried in the structure. Activation entails stepwise heterologous and autologous limited proteolysis, which makes this bond eventually accessible ${ }^{107,109}$

In contrast to funnelins and MMPs but similarly to trypsin-like serine endopeptidases ${ }^{46,107,108,110}$, astacins undergo rearrangement upon activation within an "activation domain", and the mature N-terminal segment becomes inserted and buried for its first six residues in an internal solvent-filled cavity of the catalytic domain. The N-terminus makes a solvent-mediated salt bridge with a glutamate immediately after the third zinc-binding residue (Scheme 2), the so-called "family specific residue" of astacins ${ }^{19}$. In addition to the residues of the zinc-binding motif of metzincins (see section 1 and Scheme 2), mature unbound astacins display a conserved tyrosine as a fourth proteinaceous zinc ligand (Scheme 4B), which is swung out following a "tyrosine switch" motion upon substrate or inhibitor binding, as well as in the zymogen ${ }^{107}$.

Other reported zymogen structures of the family are those of pro-meprin $\beta$ and pro-myroilysin (Table 1). The former has a very similar pro-segment to astacin, which is just ten residues longer and partially runs along the front surface of vicinal TRAF domain (found in tumor necrosis factor receptor-associated factors) before covering the catalytic-domain cleft ${ }^{111}$. The aspartate-switch residue of pro-meprin $\beta$ is $\mathrm{D}^{52}$. Similarly, pro-myroilysin has a 37-residue pro-segment that runs along the molecular surface of the upper sub-domain of the catalytic domain instead of a vicinal domain. Notably, the aspartate-switch aspartate is here replaced by a cysteine $\left(\mathrm{C}^{26} ;{ }^{112}\right)$, thus mimicking mammalian MMPs (see section 6).

\section{FRAGILYSINS}

The fragilysins are a metzincin family restricted to four members: three closely-related isoforms (fragilysin-1, -2 and $-3 ;>95 \%$ sequence identity) and metalloproteinase II ( $\sim 25 \%$ identity). They are virulence factors exclusively encoded by a single pathogenicity island of enterotoxigenic Bacteroides fragilis and are not found in commensal strains or any other organism. Enterotoxigenic Bacteroides fragilis is the most frequent disease-causing anaerobe in the intestinal tract of humans and livestock ${ }^{113}$ and fragilysins cleave E-cadherin, which is crucial for cell-to-cell contacts, thus facilitating bacterial penetration of the intestinal epithelium. This causes abscesses and inflammation and increases the risk of gastrointestinal cancer ${ }^{114}$. Pro-fragilysins contain a catalytic domain preceded by a pro-segment, which plays a role in both the latency and folding stability of the catalytic domain ${ }^{57,115}$. The latter contains the characteristic structural element of the metzincins (see section 6) and is closest to ADAMs/adamalysins, despite low sequence similarity ${ }^{57}$. Taken together with the extremely limited distribution of fragilysins, this suggests that the catalytic domain of these MPs may derive from an adamalysin/ADAM xenolog coopted by $B$. fragilis, which colonizes the gut of mammals ${ }^{57}$.

The 194-residue pro-segment of pro-fragilysin-3 consists of a globular part with a central antiparallel twisted seven-stranded $\beta$-sheet, which laterally attaches to the 186-residue catalytic domain on its right-hand side through one face (Scheme 4A). This interface further contains two helices upstream and one helix downstream of the last $\beta$-strand. Attached to the opposite face of the sheet is an N-terminal three-stranded mixed $\beta$-sheet, whose strands are orthogonal to those of the long sheet, and an extra helix inserted between the first two strands. After this globular part, the pro-segment chain adopts an extended conformation for its C-terminal segment, which runs in the opposite orientation to a substrate and performs an antiparallel $\beta$-strand interaction with the upper-rim strand of the catalytic domain on the non-primed side of the cleft. A prominent bulge is found where the pro-segment chain passes over the catalytic zinc. This causes the $\mathrm{Y}^{191}$ and $\mathrm{D}^{194}$ side chains to penetrate the catalytic moiety and the latter to coordinate the catalytic zinc ion from the top in a bidentate manner in substitution of the catalytic solvent ${ }^{57}$. Accordingly, the mechanism of latency in fragilysins follows an aspartate 
switch as described for astacins (section 7) and karilysin (section 6). Eight residues of the pro-segment/catalytic domain linker are flexible in pro-fragilysin-3, which likely facilitates proteolytic activation to yield the mature MP starting at $\mathrm{A}^{212}$. This zymogenic mechanism was confirmed by the very similar structure of pro-metalloproteinase II ${ }^{116}$.

\section{THURINGILYSINS}

The name of this bacterial metzincin family was dubbed based on immune inhibitor A1 (InhA1) peptidase from Bacillus thuringiensis ${ }^{19}$, which was reported in the 1970 s to interfere with the humoral defense system of saturniid insects by degrading antibacterial host proteins upon infection ${ }^{117}$. Close orthologs and paralogs, which include InhA1, InhA2 and InhA3 variants, are found within bacteria of the Bacillus cereus group, and more distant relatives are the PrtV peptidases from several Vibrio species. In particular, Bacillus anthracis produces BaInhA2 and BaInhA1, which modulates the secretome of the causal agent of anthrax ${ }^{118}$.

The only zymogenic thuringilysin structure reported to date is that of pro- $B a \operatorname{Inh} A 2$. The secreted protein has a 767-residue four-domain architecture containing a 309-residue catalytic domain, the longest for a metzincin (see section 6). It is preceded by an 84-residue pro-segment, which wraps around and interacts with the catalytic domain through a large surface (Scheme 4C). A VEG domain (found in viral envelope glycoproteins) and a MAM domain (reported from meprin $\alpha$ and $\beta$, A5 protein, and receptor-type tyrosine-protein phosphatase $\mu$ ) grafted into the latter are found downstream of the catalytic domain (Scheme $4 \mathrm{C} ;{ }^{58}$ ).

The first 18 residues of the pro-segment of pro- $B a \operatorname{InhA} 2$ are cleaved off after protein synthesis to yield a functional zymogen, which starts at residue $\mathrm{N}^{50}$ and binds to the primed side of the active-site cleft like a downstream reaction product (see Scheme 1, IV). Its deprotonated $\alpha$-amino group ligands the catalytic zinc ion instead of the catalytic solvent, and its side chain points into cleft sub-site $\mathrm{S}_{1}$ '. Thereafter, the pro-segment runs in extended conformation for its first four residues along the cleft and shapes a small globular moiety containing two perpendicular helices. This moiety is attached to the right side of the catalytic domain, and then passes across the non-primed side of the cleft and forms a third helix at its leftmost end (Scheme 4C). This helix runs downward along the left catalytic domain surface and leads to the final maturation cleavage point $\left(\mathrm{E}^{133}-\mathrm{Q}^{134}\right)$ in the lower back part of the molecule, on top of the VEG domain. Overall, this mechanism of latency maintenance in MPs through the pro-segment N-terminus is probably shared with other thuringilysins, including more distant relatives from Vibrio sp. ${ }^{58}$.

\section{THERMOLYSINS}

Thermolysins are found across Gram-positive and -negative bacteria, as well as in archaea and fungi, and they have high biotechnological interest. As they are produced as virulence factors by several pathogens, they have also been identified as promising drug targets ${ }^{119}$. Thermolysins are the structurally most extensively characterized MPs and belong to the gluzincin clan $13,21,22,120$. Gluzincins share with metzincins the gross architecture of the upper sub-domain of the catalytic domain, including an at least three-stranded $\beta$-sheet with an antiparallel upper-rim strand, the backing helix and the active-site helix with the short HEXXH zinc-binding motif. However, they differ in the lower sub-domains, which contain five helices in thermolysins ${ }^{120}$ and include a characteristic third zinc-liganding glutamate within a "glutamate helix" that runs below and oblique to the active-site helix in an antiparallel manner (Scheme 4D,E). Thermolysins split into a majority with large pro-segments spanning $\sim 160-260$ residues, which are intramolecular chaperones, inhibit cognate mature peptidases in trans and influence their secretion; and a minority with short pro-segments of $\sim 50-60$ residues ${ }^{47,59,121}$. In the former, the catalytic domains encompass $\sim 320$ residues and contain structural calcium ions; in the latter, the catalytic domains span $\sim 290$ residues, have extended primed sub-sites and lack calcium ions. The zymogen structure of one representative of each group has been published (see Table 1).

Pro-protealysin from Serratia proteomaculans has a short 50-residue pro-segment, which forms a separate moiety of two antiparallel helices that is placed on top of the primed-side of the active-site cleft (Scheme 4D; ${ }^{122}$ ). From this scaffold, an N-terminal segment runs like a substrate in extended conformation above the catalytic zinc- but does not contact the metal — and binds the upper-rim strand on the non-primed side. Inspection of the flexible junction between the pro-segment and the catalytic domain (Scheme 4D) suggests that activation cleavage and pro-segment removal should not cause significant rearrangement of the mature N-terminus.

Vibriolysin from Pseudoalteromonas sp., which was reported in a zymogenic complex obtained by autolysis, has a long 180-residue pro-segment laterally attached through a large interface to the lower sub-domain of the catalytic domain (Scheme 4E; ${ }^{59}$ ). The pro-segment is hinge-shaped and consists of two domains: an FTP domain, as found in fungalysin and thermolysin pro-peptides; and a PepSY domain, present in peptidase pro-peptides and Bacillus subtilis YpeB sporulation protein. FTP is an $\alpha / \beta$-sandwich reminiscent of cystatins (cysteine peptidase inhibitors) and ferredoxins, which comprises a twisted antiparallel five-stranded $\beta$-sheet, whose concave side accommodates two consecutive helices inserted between the first two sheet strands. Perpendicular to FTP and connected by a linker containing a short helix, downstream PepSY has a similar architecture to FTP, but the sheet is four-stranded. PepSY makes fewer interactions with the catalytic domain than FTP-mainly through the loop connecting the two central strands of the sheet. It serves as a scaffold for the introduction of the last three pro-segment residues into the non-primed side of the active-site cleft, where they occupy sub-sites $\mathrm{S}_{3}-\mathrm{S}_{1}$ and block them for substrate binding. The main determinant of inhibition is the C-terminal carboxylate of the last pro-segment residue, $\mathrm{H}^{204}$, which replaces the catalytic solvent molecule in the zinc-coordination sphere in a monodentate manner, similarly to an upstream cleavage product (see Scheme 1, IV and Scheme 4E).

The catalytic domain in the zymogenic complex is in overall competent conformation, as revealed by comparison with isolated mature vibriolysin ${ }^{59}$. The $\mathrm{N}$-terminal residue $\mathrm{A}^{205}$ is $\sim 32 \AA$ apart from $\mathrm{H}^{204}$, which indicates that autolysis of the intact zymogen to yield the zymogenic complex caused large conformational rearrangement under 
displacement of the mature N-terminus out of the cleft (see Scheme 2). The zymogen, of unknown structure, is likely in a high-energy state, so that activation may lead to a relaxed conformation of high thermal stability ${ }^{59}$. The first eight $\mathrm{N}$ terminal residues of the mature catalytic domain form a $\beta$-strand, which contributes to a three-stranded $\beta$-sheet within the upper sub-domain that is part of the $\sim 30$-residue segment absent from thermolysins with short pro-segments $\left({ }^{122}\right.$ and Scheme 4D,E). This sheet is also found in the structure of mature family prototype, thermolysin of Bacillus thermoproteolyticus (Protein Data Bank access code [PDB] 4TLN; ${ }^{120}$ ) and the other mature structures reported to date ${ }^{121}$, which are all forms with long pro-segments. Thus, the rearrangement of the mature N-terminus may be a general mechanism for these thermolysins. Overall, the latency mechanisms of thermolysins with short and long pro-segments are markedly different, which is striking given the close similarity of the downstream catalytic domains. Moreover, some species encode both types of thermolysins, e.g. Streptomyces avermitilis, Streptomyces coelicolor, Xanthomonas axonopodis and Methanosarcina acetivorans ${ }^{121}$.

\section{MINIGLUZINCINS}

With only $\sim 105$ residues, members of this family are exclusively present in thermophilic prokaryotes. They have the minimal scaffold required for MP activity and contain a glutamate helix, as in gluzincins. However, the zincbinding glutamate is here replaced by a histidine (Scheme 2 and ${ }^{45}$ ). Among minigluzincins, 110-residue selecase from Methanocaldococcus jannaschii selectively cleaved casein at a single site ${ }^{44}$. Uniquely for peptidases, this MP showed vanishing enzymatic activity when its concentration increased. This owed to oligomerization as proven by structural and biophysical studies. Only the monomer was active, and dimers, tetramers and octamers corresponded to self-inhibiting latent species. Even more strikingly, inactive concentrated protein reversibly became active by simple dilution with buffer, for inactive oligomers dissociated to active monomers. Two more minigluzincins, abylysin from Pyrococcus abyssi and jannalysin from M. jannaschii, were exclusively isolated as zymogens and solved for their crystal structures ${ }^{45}$.

The structure of 105-residue pro-abylysin shows the overall competent moiety of an MP catalytic domain, including a zinc site and active-site cleft with reasonable geometry. It contains the common structural elements of competent gluzincins: an upper sub-domain consisting of a three-stranded $\beta$-sheet with an upper-rim strand, a backing helix and an active-site helix with the HEXXH motif; and a lower sub-domain with a glutamate helix and a C-terminal helix (Scheme 5B). The latter is followed by a segment in extended conformation from $\mathrm{Q}^{101}$ onwards, which runs across the primed side of the cleft in reverse orientation to a substrate. It interacts with the upper-rim strand and binds the zinc through the $\mathrm{C}$-terminal carboxylate of $\mathrm{V}^{105}$ in a monodentate fashion. Accordingly, latency is here uniquely exerted by a C-terminal pro-segment of five residues.

In contrast, 110-residue pro-jannalysin, with a practically overlapping polypeptide chain with pro-abylysin (see Fig. 3B in ${ }^{45}$ ), lacks the $\mathrm{C}$-terminal extension and is $\mathrm{N}$-terminally elongated instead. This segment, however, does not account for latency. This is exerted by the last residue of the $\mathrm{C}$-terminal helix $\left(\mathrm{I}^{110}\right)$, which projects away from the molecular body and approaches the zinc-binding site — though not the metal—of a neighboring molecule through its C-terminal carboxylate, thus blocking the primed side of the cleft in trans (Scheme 5C). Accordingly, consistent with studies in solution, pro-jannalysin is a homodimer, in which latency is symmetrically exerted crosswise through respective Cterminal $\alpha$-helices. This accounts for a different mechanism of latency than in proabylysin despite substantial sequence identity among the two proteins (31\%).

Strikingly, yet other mechanisms were found for selecase ${ }^{44}$. Consistently with an active species, monomeric selecase is in a competent and functional conformation, which is very similar to the catalytic domains of pro-jannalysin and pro-abylysin, except that the active-site cleft is not blocked. In contrast, in dimeric selecase latency is symmetrically exerted through major rearrangement of the metal-binding sites, so that the third zinc-binding histidine $\left(\mathrm{H}^{80}\right)$ is pulled out of the active site. This ligand is replaced by $\mathrm{H}^{107}$ from the $\mathrm{C}$-terminal helix of the symmetric molecule, thus yielding an incompetent active site (compare Scheme 5B,C with Scheme 5D). Furthermore, two point mutants of selecase show yet diverse dimeric quaternary structures, and thus zymogenic mechanisms ${ }^{44}$. Finally, the structure of tetrameric selecase reveals that the glutamate helix and the preceding segment undergo drastic conformational rearrangement to give rise to a canonical $\beta$-ribbon structure, which removes the third histidine from the zinc coordination sphere. Four such monomers assemble to yield an almost spherical self-inhibitory particle of $\sim 70 \AA$ in diameter, in which the distorted active sites are in the particle lumen. Thus, selecase represents a unique case of metamorphic protein that reversibly exerts zymogenicity through oligomerization mediated by molecular plasticity. It has the capacity to adopt several different structures, which are all dysfunctional except for one ${ }^{44}$.

\section{FUNGALYSINS}

The archetype of this family of the gluzincin clan (Scheme 1) is Aspergillus fumigatus fungalysin alias AfuMep, a secreted 42-kDa MP that degrades extracellular matrix proteins and is considered a virulence factor in fungal diseases ${ }^{123}$. Pro-fungalysin contains a pro-segment of 227 residues, which is the longest for a structurally-characterized MP zymogen, followed by a 389-residue catalytic domain. Similar to vibriolysin (see section 10), the structure ${ }^{124}$ corresponds to an autolytic cleavage product, a zymogenic complex in which the last residue of the pro-segment $\left(\mathrm{E}^{245}\right)$ is $\sim 31 \AA$ apart from the $\mathrm{N}$-terminus of the catalytic domain. Also like in vibriolysin, the $\mathrm{N}$-terminal segment of the catalytic domain is engaged in a small $\beta$-sheet (Scheme $5 \mathrm{~A}$ ) and the rest of the catalytic domain evinces most of the structural elements characteristic of thermolysins with long pro-segments. This includes helices and strands of the upper sub-domain and the five helices of the lower sub-domain, as well as a preference to cleave before hydrophobic residues ${ }^{124}$. 
Scheme 5 - Structures of prototypic MP zymogens (III). (A) Aspergillus fumigatus fungalysin in complex with its pro-segment. The $\mathrm{C}$-terminus of the pro-segment and the $\mathrm{N}$-terminus of the catalytic domain are pinpointed by blue and purple arrows, respectively. (B) Monomeric Pyrococcus abyssi pro-abylysin. (C) Dimeric pro-jannalysin from Methanocaldococcus jannaschii. Zymogenicity is symmetrically exerted within a dimer by the C-terminal helix of one molecule acting as the pro-segment (in sandy brown) and the catalytic domain of the other molecule (in aquamarine). The rest of the dimer is depicted in white for clarity. (D) Dimeric latent selecase from M. jannaschii. For coloring, see (C). (E) Aeromonas salmonicida pro-AsaP1. Protein domains and features are rendered and colored as in Scheme 3.

A
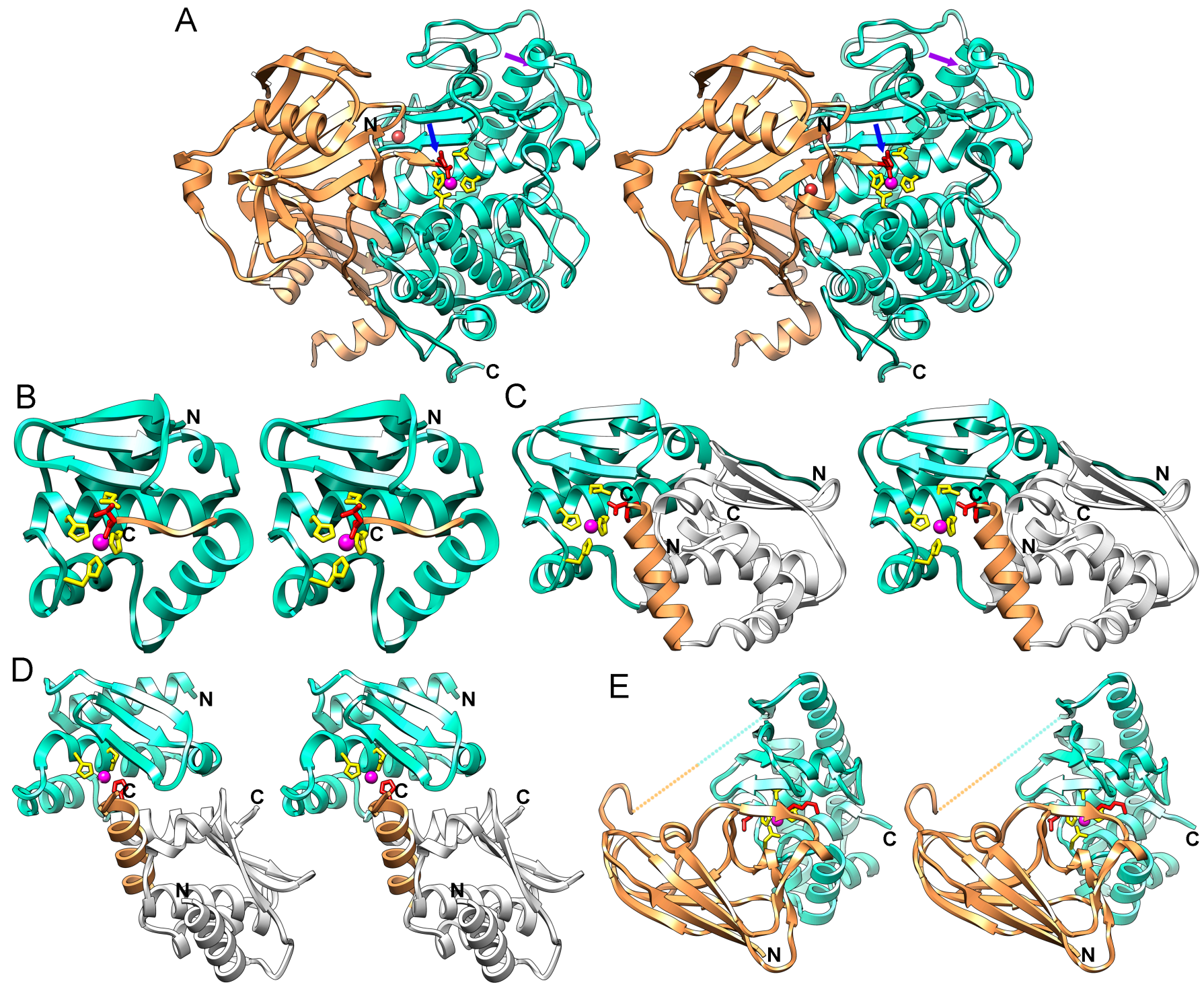

The fungalysin pro-segment consists of two $\alpha / \beta$-sandwiches, which are very similar to FTP and PepSY from the vibriolysin pro-segment, connected by a linker likewise encompassing a short helix. They are arranged with respect to the catalytic domain similarly to the MP from Vibrio, merely the C-terminal sandwich of fungalysin lacks one of the helices of PepSY and shows two extra $\beta$-strands. Its C-terminus likewise penetrates the active-site cleft, here for its four last residues, so that $\mathrm{E}^{245}$ binds the catalytic zinc ion through its $\mathrm{C}$-terminal carboxylate in a monodentate manner, similarly to an upstream reaction product (see Scheme 1, IV). Accordingly, the architectures of the catalytic domains and the latency mechanisms of fungalysins from fungi and thermolysins with large pro-segments from bacteria are equivalent, which suggests that fungalysins may be grouped with thermolysins. Both families likely share a common origin, with one family potentially resulting from horizontal gene transfer from the other, followed by subsequent spreading within a distinct kingdom.

\section{ANTHRAX LETHAL FACTOR-TYPE METALLOPEPTIDASES}

The archetypal domain of this family is the catalytic domain (residues $\mathrm{P}^{551}-\mathrm{I}^{773}$ ) of multi-domain $B$. anthracis lethal factor (PDB $1 \mathrm{~J} 7 \mathrm{~N} ;{ }^{125}$ ), which is essential for the pathogenesis of anthrax ${ }^{125}$. Lethal factor specifically cleaves mitogen-activated protein kinase kinase family members, which causes fatal inhibition of several cellular signaling pathways ${ }^{125}$. The mature lethal factor structure conforms to the architecture of gluzincins and includes a glutamate-helix with a glutamate as the third protein ligand of the catalytic zinc (see section 10 and Scheme 2).

Among the several structural relatives of the lethal factor catalytic domain is the 265-residue bacterial protein MtfA (from Mlc titration factor A), which participates in the control of the glucose-phosphotransferase sensory and regulatory system by inactivating transcriptional repressor Mlc (from makes large colonies; ${ }^{126,127}$ ). The structure of an incompetent full-length variant of MtfA from Klebsiella pneumophila with only poor aminopeptidase activity reveals that the upper-rim strand and the preceding segment within the upper sub-domain $\beta$-sheet found in lethal factor are replaced by a helical peptide $\left(\mathrm{G}^{109}-\mathrm{Q}^{118}\right)$ flanked by ten- and five-residue flexible segments, respectively. The helical peptide covers 
the non-primed side of the active-site cleft by running in the reverse direction of a substrate and $\mathrm{H}^{112}$ atom $\mathrm{N} \varepsilon 2$ coordinates the catalytic zinc replacing the solvent in a kind of "histidine-switch" reminiscent of minigluzincins (section 11 and Scheme 3B). Competent lethal factor has a helical segment $\left(\mathrm{H}^{645}-\mathrm{A}^{640}\right)$ within the loop linking the upper-rim strand with the preceding strand and $\mathrm{H}^{645}$ could correspond to $\mathrm{H}^{12}$ of MtfA, so competent lethal factor might be a valid model for functional MtfA. This suggests an unheard hypothetical latency mechanism, which would entail rearrangement of incompetent 30-residue segment $\mathrm{P}^{95}-\mathrm{Q}^{124}$ of $\mathrm{MtfA}$ to match the competent conformation of $\mathrm{D}^{633}-\mathrm{E}^{662}$ of lethal factor. In addition, other segments would undergo rearrangement in MtfA, in particular loop $\mathrm{R}^{158}-\mathrm{A}^{175}$, which connects the activesite helix with the downstream helix and partially occludes the non-primed side of the cleft when compared with the equivalent segment from lethal factor $\left(\mathrm{Y}^{695}-\mathrm{K}^{712}\right)$. However, this conformation may also be authentic in active MtfA and account for its aminopeptidase activity, which requires a small non-primed side of the cleft. Thus, in this mechanism of latency, activation would probably not be proteolytic, but rather an internal metamorphic rearrangement reminiscent of minigluzincins (section 11) through interaction with a yet unknown factor such as Mlc ${ }^{127}$.

\section{ASPZINCINS}

The name aspzincins arises from the fungal prototype, deuterolysin from Aspergillus oryzae, which was identified as a zincin with an aspartate as third zinc ligand ${ }^{23,24}$. All currently described aspzincins originate from fungi, apart from two bacterial specimens from the genus Aeromonas ${ }^{24}$. Thus, the clan aspzincins consists to date of a single MP family (Scheme 2). The only currently available zymogen structure is that of AsaP1, an extracellular toxic MP from the Gram-negative bacterium infecting salmonids and other fish, Aeromonas salmonicida ${ }^{24}$. AsaP1 is a major exotoxin that has been linked with skin ulcers and lesions, degradation of subjacent muscles and necrosis, pallor gills and anaemia ${ }^{24}$. Secreted pro-AsaP1 has an N-terminal pro-segment of $\sim 140$-residues followed by a $\sim 170$-residue catalytic domain. The exact physiological activation site, the proteolytic activators and the substrate specificity are not known ${ }^{24}$. Within the zymogen structure, which lacks 13 residues at the interface between the pro-segment and the catalytic domain, the catalytic domain shows the competent fold of mature aspzincins such as deuterolysin (PDB 1EB6; ${ }^{128}$ ) and peptidyl-lysine MP from Grifola frondosa (PDB 1G12; ${ }^{129}$ ). This indicates that activation cleavage does not lead to significant conformational rearrangement of the mature $\mathrm{N}$-terminus in aspzincins. The catalytic domain contains a mixed four-stranded $\beta$-sheet with an upper-rim strand and five helices, which includes an active-site helix, in a large upper sub-domain that extends into the space occupied by the back of the lower sub-domains in other zincins (Scheme 5E). Three helices are found within a small lower sub-domain. One of them is topologically similar to the glutamate helix of gluzincins but it corresponds to the Cterminal helix of the catalytic domain and does not provide the third protein zinc ligand. Instead, a zinc-binding aspartate is provided by a loop region downstream of the active-site helix as in metzincins (Scheme 2). The pro-segment, which acts as an intramolecular chaperone ${ }^{24}$, is an elongated open $\beta$-barrel of immunoglobulin fold, which consists of two threestranded antiparallel $\beta$-sheets capped on one side by a small two-stranded antiparallel sheet. Connecting one strand of either three-stranded sheet, a long 26-residue loop $\left(\mathrm{G}^{74}-\mathrm{A}^{99}\right)$ projects away from the barrel surface and inserts into the cleft of AsaP1. In particular, segment $\mathrm{A}^{82}-\mathrm{A}^{87}$ is inserted in extended conformation mimicking a productive Michaelis complex. It occupies sub-sites $\mathrm{S}_{3}-\mathrm{S}_{3}$ ' and interacts with the upper-rim strand above the cleft, both on the primed and non-primed sides. In particular, $\mathrm{L}^{83}$ inserts into $\mathrm{S}_{2}$ and $\mathrm{K}^{85}$ penetrates specificity pocket $\mathrm{S}_{1}{ }^{\prime}$, which matches the specificity of mushroom family members $\left({ }^{24}\right.$; Scheme $\left.5 \mathrm{E}\right)$.

Because the structure of pro-AsaP1 was obtained with an inert mutant replacing the general base/acid glutamate, which was unable to cleave the pro-segment, it was suggested that the crystallized complex would correspond to a trapped intermediate ${ }^{24}$. In this case, physiological self-cleavage of the wild-type MP, i.e. upstream of $\mathrm{K}^{85}$, would yield a functional zymogen operating similarly to pro-BaInhA2 (see section 9) or thermolysins with long pro-segments and fungalysins (sections 10 and 12), in that either side of the cleft would be blocked and the zinc coordinated by the deprotonated $\alpha$-amino group of $\mathrm{K}^{85}$ or the carboxylate of $\mathrm{I}^{84}$. However, such a mechanism would be much more plausible if an N- or C-terminal peptide from the pro-segment were cleaved, as found in the aforementioned three families, rather than a peptide within an independent folding unit.

Thus, the structure might also correspond to a true zymogen, which would be unique for all the MPs reviewed here and rather reminiscent of "standard-mechanism" inhibitors of serine endopeptidases ${ }^{130-132}$ and some MPs ${ }^{25}$. Similarly, the pro-segment of pro-AsaP1 would form an operative Michaelis complex with the catalytic domain, so that it should actually be cleaved following thermodynamic criteria (see Scheme 1, II). However, this cleavage would occur only very slowly as the intact and cleaved pro-segment would be equally potent inhibitors of the catalytic domain. Thus, the prosegment would act as an energy sink: the system would behave as if it were in an equilibrium between the complex and the free pro-segment (cleaved or uncleaved) plus the catalytic domain ${ }^{130,132}$. Consistent with this hypothesis, the closest structural relative of the pro-AsaP1 pro-segment is an intracellular peptidase inhibitor of subtilisin-type serine endopeptidases from Bacillus subtilis, which was suggested to follow the standard mechanism of inhibition ${ }^{133}$. This points to a possible evolutionary origin of the pro-segment of bacterial aspzincins as a peptidase inhibitor co-opted from another bacterium to function as a latency-maintaining pro-segment

Finally, as to the general validity of either mechanism for aspzincins, the pro-segment sequences of the two Aeromonas species reported do not share significant sequence identity with those from fungi ${ }^{24}$, so that variable mechanisms of latency are conceivable.

\section{SUMMARY AND OUTLOOK}

Zymogenicity is a widespread strategy for the regulation of peptidase activity. Structural studies of 60 proteins from eleven MP families reveal that while catalytic domains share the gross architecture and a set of common structural 
features, a wide range of latency mechanisms is observed. These involve physically blocking or distorting the active site, and thus inevitably affect the access of substrates. Short or long, mostly N-terminal pro-segments, spanning from peptides without defined tertiary structure outside the zymogen to one or two independently folded domains, carry out the function. The N-termini of the mature catalytic domains after activation may or may not undergo large rearrangement. In particular, the pro-segments of funnelins shield, but do not enter, the active site. Those of LytM/lysostaphin/LasA-MPs plus thermolysins with short pro-segments and those of MMPs, fragilysins plus astacins run across the active-site cleft in the same or opposite directions to a substrate, respectively. With the exception of thermolysins with short pro-segments, the five latter MPs employ particular residues (cysteine, aspartate, glutamate and asparagine) as switches to replace the catalytic solvent. In astacins, an aspartate switch is the rule and a cysteine switch is the exception, the opposite holds for MMPs. In LytM/lysostaphin-MPs, asparagine and glutamate switches have been described but low conservation of these residues points to other potential binders in other family members.

In bacterial apzincins, the standard mechanism of certain protein inhibitors of peptidases might have been adapted for zymogenicity: a loop protruding from the pro-segment moiety would be inserted across the entire active-site cleft like a substrate, but effectively not cleaved. Alternatively, a first cleavage here would generate the competent aspzincin zymogen, in which either side of the cleft would be blocked and the zinc coordinated by the new $\alpha$-amino or carboxylate group, as found in thuringilysins and long-pro-segment thermolysins plus fungalysins, respectively. In the latter two, the mature N-terminus of the catalytic domain is rearranged and positioned widely apart from the last prosegment residue, possibly following the transition from a high-energy metastable zymogen to a low-energy stable mature catalytic domain. In anthrax lethal factor-type MPs, latency may be exerted by an intramolecular segment above the activesite cleft. This segment blocks the zinc in the zymogen through a histidine and becomes rearranged in the mature form without proteolytic cleavage, possibly through interactions with a binding partner. Moreover, within minigluzincins, latency of only three different MPs is exerted by C-terminal peptides or helices according to at least six different mechanisms, which involve oligomerization. Altogether, the plethora of mechanisms of zymogenicity described for MPs, even within the same family, predicts that yet more architectures and mechanisms of latency can be expected in the future, as already anticipated 20 years ago ${ }^{42}$.

Finally, the lessons learned from the zymogenic structures are susceptible to contribute to the development of new drugs to modulate their activity in vivo. In particular, pro-segments have been assayed as inhibitors in trans (see also section 3 ) in members of the adamalysin/ADAM family ${ }^{134,135}$. Other recent approaches contemplate the usage of small molecules or monoclonal antibodies to prevent zymogen activation through pro-segment removal, as recently shown for MMP-9 ${ }^{136-138}$. Thus, zymogen-based strategies are likely to provide orthogonal approaches to conventional drug discovery strategies, which target active-site clefts or exosites. 


\section{AUTHOR INFORMATION}

${ }^{1}$ These authors contributed equally and share first authorship.

a Present address: Max F. Perutz Laboratories; University of Vienna; Campus Vienna Biocenter 5; 1030 Vienna (Austria).

\section{Corresponding Author}

*E-mail: xgrcri@ibmb.csic.es; Tel.:(+34) 934020 186. Homepage: https://sbu.csic.es/research-groups/proteolysis-lab

\section{ORCID}

F. Xavier Gomis-Ruth: 0000-0002-6848-6874; https://scholar.google.es/citations?user=w-SQWtIAAAAJ\&hl=en

\section{Notes}

The authors declare no competing financial interest.

\section{Biographies}

Joan L. Arolas received his Ph.D. in 2005 from the Autonomous University of Barcelona (Catalonia, Spain) after studying the folding and design of small disulfide-rich protease inhibitors under the supervision of F.X. Aviles and S. Ventura. After a postdoctoral stay at the same university and further ones at the University of Munich (Germany) with C.P. Sommerhoff and the Max-Planck Institute of Biochemistry in Martinsried (Germany) with T. Holak and R. Huber, he joined the group of F.X. Gomis-Rüth at the Institute of Molecular Biology of Barcelona in 2009 to work on structural biology of proteases, in particular of metalloproteases and their mechanisms of latency. Since 2015, he is a senior staff scientist in the group of K. Djinovic at the University of Vienna, where he focuses on structural biology of the cytoskeleton.

Theodoros Goulas performed his Ph.D. thesis in 2008 on protein biochemistry and biotechnology under the supervision of G.R. Gibson at the University of Reading (UK). In 2009, he joined the group of F.X. Gomis-Rüth at the Institute of Molecular Biology of Barcelona, where he is senior research associate since 2014. He is author of 23 publications in the field of structural and biochemical characterization of host-microbiome interactions.

Anna Cuppari received her M.Sc. in structural and molecular cell biology from the State University of Milan (Italy) in 2008. She obtained her Ph.D. in structural biology at the University of Barcelona in 2016 and is currently working in the group of F.X. Gomis-Rüth as a postdoctoral scientist with the aim of better characterizing the molecular determinants of function and regulation of proteolytic processes.

F. Xavier Gomis-Rüth performed his B.Sc and M.Sc. in chemical engineering in 1989 at the Institut Químic de Sarrià from the University Ramon Llull in Barcelona (Catalonia, Spain). In 1989-1992, he worked in protein crystallography of proteolytic enzymes at the Max-Planck Institute of Biochemistry under the supervision of W. Bode and R. Huber. In 1992, he obtained his Ph.D. from the University of Munich (Germany) and performed postdoctoral stays at the Autonomous University of Barcelona, the Max-Planck Institute of Biochemistry and the Institute of Molecular Biology of Barcelona, where he became tenured assistant professor in 1999 and set up the Proteolysis Laboratory. Promotions to associate professor and full professor followed in 2004 and 2008, respectively. He has published +130 SCI-indexed peerreviewed scientific articles, which have been cited $+10,000$ times and given rise to an H-index of 51 . His research focuses on the molecular analysis of proteolytic enzymes, their regulation and inhibition, and of host-microbiome interactions. He was deputy director of the institute and is presently administrative director of the Structural Biology Unit, which was recognized in 2015 as a "María de Maeztu" Unit of Excellence by the Spanish Ministry of Economy and Competitiveness.

\section{ACKNOWLEDGEMENTS}

This study was funded in part by grants from Spanish and Catalan public agencies (BFU2015-64487-R; MDM-20140435 and 2017SGR00003). T.Go. acknowledges a "Juan de la Cierva" research contract (JCI-2012-13573) from the Spanish Ministry of Economy and Competitiveness. The Structural Biology Unit of IBMB is a "María de Maeztu" Unit of Excellence of the Spanish Ministry of Economy, Industry and Competitiveness.

\section{ABBREVIATIONS}

ADAM name of a family of metallopeptidases (a disintegrin and a metallopeptidase)

FTP domain found in fungalysin and thermolysin pro-peptides

InhA[1,2,3] immune inhibitor $\mathrm{A}[1,2,3]$

MAM domain found in meprin $\alpha$ and $\beta$, A5 protein, and receptor-type tyrosine-protein phosphatase $\mu$

Mlc protein associated with making large colonies

MMP matrix metalloprotease

MP metallopeptidase

MtfA Mlc-titration factor A

PDB protein data bank at www.pdb.org

PepSY domain present in peptidase pro-peptides and Bacillus subtilis sporulation protein YpeB

TRAF domain of tumor necrosis factor receptor-associated factors

VEG domain found in viral envelope glycoproteins 
Table 1 - Protein Data Bank entries of metallopeptidase zymogens containing at least the pro- and catalytic domains.

\section{Peptidase}

Organism

\section{Metzincins}

Astacins

Astacin $\left(\mathrm{E}^{142} \mathrm{~A}\right)^{b}$

Meprin $\beta$

Myroilysin

Matrix metalloproteinases

$\begin{array}{ll}\text { MMP-1 }\left(\mathrm{E}^{219} \mathrm{~A}\right) & \text { H. sapiens (Animalia) } \\ \text { MMP-2 }\left(\mathrm{E}^{404} \mathrm{Q} / \mathrm{A}\right) & \text { H. sapiens (Animalia) } \\ \text { MMP-3 } & \text { H. sapiens (Animalia) } \\ \text { MMP-7 }\left(\mathrm{E}^{215} \mathrm{~A}\right) & \text { H. sapiens (Animalia) } \\ \text { MMP-9 }^{c} & \text { H. sapiens (Animalia) } \\ \text { Karilysin }\left(\mathrm{E}^{156} \mathrm{~A}\right) & \text { T. forsythia (Bacteria) }\end{array}$

Fragilysins

Fragilysin-3

Metalloproteinase II $\left(\mathrm{E}^{352} \mathrm{~A}\right)$

Thuringilysins

Immune inhibitor A2 $\left(\mathrm{E}^{380} \mathrm{~A}\right) \quad$ B. anthracis (Bacteria)

\section{Gluzincins}

Thermolysins

Protealysin $\left(\mathrm{E}^{163} \mathrm{~A}\right)$

S. proteomaculans (Bacteria)

Vibriolysin $\mathrm{MCP}-02\left(\mathrm{E}^{346} \mathrm{~A}\right) \quad$ Pseudoalteromonas sp. (Bacteria)

Minigluzincins

$\begin{array}{ll}\text { Abylysin } & \text { P. abyssi (Archaea) } \\ \text { Jannalysin } & \text { M. jannaschii (Archaea) } \\ \text { Selecase } & \text { M. jannaschii (Archaea) }\end{array}$

Fungalysins

Fungalysin

A. fumigatus (Fungi)

Anthrax lethal factor-type MPS

MtfA

K. pneumoniae (Bacteria)

Aspzincins

Aspzincins

AsaP1 ( $\left.E^{294} \mathrm{Q} / \mathrm{A}\right)$

A. salmonicida (Bacteria)

\section{LytM/lysostaphin-MPs}

$\begin{array}{ll}\text { LytM } & \text { S. aureus (Bacteria) } \\ \text { Csd3 } & \text { H. pylori (Bacteria) } \\ \text { NMB0315 } & \text { N. meningitidis (Bacteria) } \\ \text { VC0503 } & \text { V. cholera (Bacteria) }\end{array}$

Funnelins

A/B-type Funnelins
PDB codes ${ }^{a}$; UniProt code; Ref.

\author{
3LQ0; Q9U918; 107 \\ 4GWM; Q16820; ${ }^{111}$ \\ 5CZW,5GWD; B5B0E6; ${ }^{112}$
}

1SU3; P03956; ${ }^{139}$

1EAK,1CK7,1GXD; P08253; 92,140

1SLM; P08254; ${ }^{141}$

2MZE,2MZH,2MZI,5UE2,5UE5; P09237; 142,143

1L6J,5TH6,5TH9,5UE3,5UE4; P14780;

4R3V; D0EM77; ${ }^{145}$

3P24; O86049; ${ }^{57,115}$

4ON1; O68424; ${ }^{114}$

4YU5,4YU6; WP_001253006.1 ${ }^{d}{ }^{58}$

2VQX; Q5MJ80; ${ }^{122}$
NQY,3NQZ; A1DRD5; 59

4JIU; Q9V1Y2; ${ }^{45}$

4JIX; Q57587; ${ }^{45}$

4QHG,4QHH,4QHI,4QHJ; Q58610; ${ }^{44}$

4K90; P46075; ${ }^{124}$

3KHI; А6TB83; 127

2X3A,2X3B,2X3C; Q8GMV9; ${ }^{24}$

1QWY; O33599; ${ }^{54}$ 4RNY, 4RNZ; O25247; ${ }^{83}$ 3SLU; E0N688; ${ }^{84}$ 2GU1; Q9KUL5; ${ }^{85}$ 


\begin{tabular}{|c|c|c|}
\hline \multirow[t]{3}{*}{ PCPA1 } & S. scrofa (swine; Animalia) & $1 \mathrm{PCA}^{e} ; \mathrm{P} 09954 ;{ }^{146}$ \\
\hline & H. sapiens (Animalia) & 4UF4; P15085 \\
\hline & B. taurus (cow; Animalia) & 1PYT; P00730; ${ }^{147}$ \\
\hline PCPA2 & H. sapiens (Animalia) & 1AYE; P48052; ${ }^{148}$ \\
\hline PCPA4 & H. sapiens (Animalia) & 2BOA; Q9UI42; ${ }^{74}$ \\
\hline НаРCPA & $\begin{array}{l}\text { H. armigera (cotton bollworm; } \\
\text { Animalia) }\end{array}$ & 1JQG; O97389; ${ }^{149}$ \\
\hline \multirow[t]{2}{*}{ PCPB1 } & S. scrofa (swine; Animalia) & 1NSA,3GLJ; P09955; ${ }^{.2,150}$ \\
\hline & H. sapiens (Animalia) & 1KWM; P15086; ${ }^{151}$ \\
\hline \multirow[t]{2}{*}{ PCPB2/TAFI } & H. sapiens (Animalia) & $\begin{array}{c}\text { 3D66,3D67,3D68,4P10,5HVF,5HVG, } \\
\text { 5HVH; Q96IY4; }{ }^{152-154}\end{array}$ \\
\hline & B. taurus (cow; Animalia) & 3DGV; Q2KIG3; ${ }^{155}$ \\
\hline
\end{tabular}

${ }^{a}$ See the Protein Data Bank (PDB) at www.pdb.org; codes in bold correspond to structures discussed in the text and depicted in Schemes 3-5.

${ }^{b}$ In parenthesis, general base/acid positions that are mutated in any of the structures deposited.

${ }^{c}$ All structures except that of PDB 1L6J lack the three fibronectin type-II domains inserted into the catalytic moiety.

${ }^{d}$ GenBank accession number.

${ }^{e}$ This structure was obtained before the protein sequence was available and thus contains 41 mutations.

Search completed on 14 November 2017. 


\section{REFERENCES}

(1) Barrett, A. J.; Rawlings, N. D.; Salvesen, G.; Woessner, J. F. In Handbook of Proteolytic Enzymes; Rawlings, N. D.;Salvesen, G., Eds.; Academic Press: Oxford (UK), 2013; Vol. 1; p. Ii-Iiv.

(2) Neurath, H. In Proteases and biological control.; Reich, E.;Rifkins, D. B.;Shaw, E., Eds.; Cold Spring Harbor Laboratory Press: New York, 1975; Vol. 2; p. 51-64.

(3) Linderstrøm-Lang, K.; Ottesen, M. Formation of plakalbumin from ovoalbumin. Compt. Rend. Trav. Lab. Carlsberg, Ser. Chim. 1949, 26, 403-442.

(4) Bryan, P. N. Prodomains and protein folding catalysis. Chem. Rev. 2002, 102, 4805-4816.

(5) López-Otín, C.; Overall, C. M. Protease degradomics : a new challenge for proteomics. Nat. Rev. Mol. Cell Biol. 2002, 3, 509-519.

(6) Clark, P. Protease-mediated ectodomain shedding. Thorax 2014, 69, 682-684.

(7) Dufour, A.; Overall, C. M. Missing the target: matrix metalloproteinase antitargets in inflammation and cancer. Trends Pharmacol. Sci. 2013, 34, 233-242.

(8) Klein, T.; Eckhard, U.; Dufour, A.; Solis, N.; Overall, C. M. Proteolytic cleavage-mechanisms, function, and "omic" approaches for a near-ubiquitous posttranslational modification. Chem. Rev. 2018, 118, 1137-1168.

(9) Schechter, I.; Berger, A. On the size of active site in proteases. I. Papain. Biochem. Biophys. Res. Commun. 1967, 27, 157-162.

(10) Gomis-Rüth, F. X.; Botelho, T. O.; Bode, W. A standard orientation for metallopeptidases. Biochim. Biophys. Acta 2012, 1824, 157-163.

(11) Bayés, A.; Fernández, D.; Solà, M.; Marrero, A.; García-Piqué, S.; Avilés, F. X.; Vendrell, J.; Gomis-Rüth, F. X. Caught after the Act: A human A-type metallocarboxypeptidase in a product complex with a cleaved hexapeptide. Biochemistry 2007, 46, 6921-6930.

(12) Matthews, B. W. Structural basis of the action of thermolysin and related zinc peptidases. Acc. Chem. Res. 1988, $21,333-340$

(13) Cerdà-Costa, N.; Gomis-Rüth, F. X. Architecture and function of metallopeptidase catalytic domains. Prot. Sci. 2014, 23, 123-144.

(14) Auld, D. S. In Handbook of Proteolytic Enzymes; Rawlings, N. D.;Salvesen, G., Eds.; Academic Press: Oxford, 2013; Vol. 1; p. 370-396.

(15) Bochtler, M.; Odintsov, S. G.; Marcyjaniak, M.; Sabala, I. Similar active sites in lysostaphins and D-Ala-D-Ala metallopeptidases. Protein Sci. 2004, 13, 854-861.

(16) Grabowska, M.; Jagielska, E.; Czapinska, H.; Bochtler, M.; Sabala, I. High resolution structure of an M23 peptidase with a substrate analogue. Sci. Rep. 2015, 5, 14833.

(17) Bode, W.; Gomis-Rüth, F. X.; Stöcker, W. Astacins, serralysins, snake venom and matrix metalloproteinases exhibit identical zinc-binding environments (HEXXHXXGXXH and Met-turn) and topologies and should be grouped into a common family, the 'metzincins'. FEBS Lett. 1993, 331, 134-140.

(18) Gomis-Rüth, F. X. Catalytic domain architecture of metzincin metalloproteases. J. Biol. Chem. 2009, 284, 1535315357.

(19) Gomis-Rüth, F. X. Structural aspects of the metzincin clan of metalloendopeptidases. Mol. Biotech. 2003, $24,157-$ 202.

(20) Stöcker, W.; Bode, W. Structural features of a superfamily of zinc-endopeptidases: the metzincins. Curr. Opin. Struct. Biol. 1995, 5, 383-390.

(21) Gomis-Rüth, F. X. Structure and mechanism of metallocarboxypeptidases. Crit. Rev. Biochem. Mol. Biol. 2008, 43 , 319-345.

(22) Hooper, N. M. Families of zinc metalloproteases. FEBS Lett. 1994, 354, 1-6.

(23) Fushimi, N.; Ee, C. E.; Nakajima, T.; Ichishima, E. Aspzincin, a family of metalloendopeptidases with a new zincbinding motif. Identification of new zinc-binding sites (His(128), His(132), and Asp(164)) and three catalytically crucial residues (Glu(129), Asp(143), and $\operatorname{Tyr}(106))$ of deuterolysin from Aspergillus oryzae by site-directed mutagenesis. J. Biol. Chem. 1999, 274, 24195-24201.

(24) Bogdanovic, X.; Palm, G. J.; Schwenteit, J.; Singh, R. K.; Gudmundsdottir, B. K.; Hinrichs, W. Structural evidence of intramolecular propeptide inhibition of the aspzincin metalloendopeptidase AsaP1. FEBS Lett. 2016, 590, 32803294.

(25) Arolas, J. L.; Botelho, T. O.; Vilcinskas, A.; Gomis-Rüth, F. X. Structural evidence for standard-mechanism inhibition in metallopeptidases from a complex poised to resynthesize a peptide bond. Angew. Chem. Int. Ed. Engl. 2011, 50, 10357-10360.

(26) Yan, C.; Boyd, D. D. Regulation of matrix metalloproteinase gene expression. J. Cell Physiol. 2007, 211, 19-26.

(27) Hadler-Olsen, E.; Fadnes, B.; Sylte, I.; Uhlin-Hansen, L.; Winberg, J.-O. Regulation of matrix metalloproteinase activity in health and disease. FEBS J. 2011, 278, 28-45.

(28) Rawlings, N. D.; Tolle, D. P.; Barrett, A. J. Evolutionary families of peptidase inhibitors. Biochem. J. 2004, 378 , 705-716.

(29) Garcia-Ferrer, I.; Marrero, A.; Gomis-Rüth, F. X.; Goulas, T. $\alpha_{2}$-Macroglobulins: structure and function. Subcell. Biochem. 2017, 83, 149-183.

(30) Goulas, T.; Garcia-Ferrer, I.; Marrero, A.; Marino-Puertas, L.; Duquerroy, S.; Gomis-Rüth, F. X. Structural and functional insight into pan-endopeptidase inhibition by $\alpha_{2}$-macroglobulins. Biol. Chem. 2017, 398, 975-994. 
(31) Marrero, A.; Duquerroy, S.; Trapani, S.; Goulas, T.; Guevara, T.; Andersen, G. R.; Navaza, J.; Sottrup-Jensen, L.; Gomis-Rüth, F. X. The crystal structure of human $\alpha_{2}$-macroglobulin reveals a unique molecular cage. Angew. Chem. Int. Ed. 2012, 51, 3340-3344.

(32) Goulas, T.; Garcia-Ferrer, I.; García-Piqué, S.; Sottrup-Jensen, L.; Gomis-Rüth, F. X. Crystallization and preliminary X-ray diffraction analysis of eukaryotic $\alpha_{2}$-macroglobulin family members modified by methylamine, proteases and glycosidases. Mol. Oral Microbiol. 2014, 29, 354-364.

(33) Jackson, H. W.; Defamie, V.; Waterhouse, P.; Khokha, R. TIMPs: versatile extracellular regulators in cancer. Nat. Rev. Cancer 2017, 17, 38-53.

(34) Nagase, H.; Visse, R.; Murphy, G. Structure and function of matrix metalloproteinases and TIMPs. Cardiovasc. Res. 2006, 69, 562-573.

(35) Trillo-Muyo, S.; Martínez-Rodríguez, S.; Arolas, J. L.; Gomis-Rüth, F. X. Mechanism of action of a Janus-faced single-domain protein inhibitor simultaneously targeting two peptidase classes. Chem. Sci. 2013, 4, 791-797.

(36) Fernández, D.; Pallarés, I.; Covaleda, G.; Avilés, F. X.; Vendrell, J. Metallocarboxypeptidases and their inhibitors: recent developments in biomedically relevant protein and organic ligands. Curr. Med. Chem. 2013, 20, 1595-1608. Tarma, B. Jamdar, S. N. Ghosh, B. Yadav, P · Kumar, A. Kundu, S ; Goyal, V. D; Makde, R. D. Active site gate of M32 carboxypeptidases illuminated by crystal structure and molecular dynamics simulations. Biochim. Biophys. Acta - Prot. Proteomics 2017, 1865, 1406-1415.

(38) Rawlings, N. D.; Barrett, A. J.; Finn, R. Twenty years of the MEROPS database of proteolytic enzymes, their substrates and inhibitors. Nucleic Acids Res. 2016, 44, D343-D350.

(39) Fernández-Gamba, A.; Leal, M. C.; Morelli, L.; Castaño, E. M. Insulin-degrading enzyme: structure-function relationship and its possible roles in health and disease. Curr. Pharm. Des. 2009, 15, 3644-3655.

(40) Russo, S.; Baumann, U. Crystal structure of a dodecameric tetrahedral-shaped aminopeptidase. J. Biol. Chem. 2004, 279, 51275-51281.

(41) Remaut, H.; Bompard-Gilles, C.; Goffin, C.; Frere, J. M.; Van Beeumen, J. Structure of the Bacillus subtilis Daminopeptidase DppA reveals a novel self-compartmentalizing protease. Nat. Struct. Biol. 2001, 8, 674-678.

(42) Khan, A. R.; James, M. N. Molecular mechanisms for the conversion of zymogens to active proteolytic enzymes. Prot. Sci. 1998, 7, 815-836.

(43) Neurath, H. The activation of zymogens. Adv. Prot. Chem. 1957, 12, 319-386.

(44) López-Pelegrín, M.; Cerdà-Costa, N.; Cintas-Pedrola, A.; Herranz-Trillo, F.; Bernadó, P.; Peinado, J. R.; Arolas, J. L.; Gomis-Rüth, F. X. Multiple stable conformations account for reversible concentration-dependent oligomerization and autoinhibition of a metamorphic metallopeptidase. Angew. Chem. Int. Ed. 2014, 53, 1062410630.

(45) López-Pelegrín, M.; Cerdà-Costa, N.; Martínez-Jiménez, F.; Cintas-Pedrola, A.; Canals, A.; Peinado, J. R.; MartíRenom, M. A.; López-Otín, C.; Arolas, J. L.; Gomis-Rüth, F. X. A novel family of soluble minimal scaffolds provides structural insight into the catalytic domains of integral-membrane metallopeptidases. J. Biol. Chem. 2013, 288, 21279-21294.

(46) Gomis-Rüth, F. X.; Trillo-Muyo, S.; Stöcker, W. Functional and structural insights into astacin metallopeptidases. Biol. Chem. 2012, 393, 1027-1041.

(47) Demidyuk, I. V.; Shubin, A. V.; Gasanov, E. V.; Kostrov, S. V. Propeptides as modulators of functional activity of proteases. Biomol. Concepts 2010, 1, 305-322.

(48) Winther, J. R.; Sorensen, P. Propeptide of carboxypeptidase Y provides a chaperone-like function as well as inhibition of the enzymatic activity. Proc. Natl. Acad. Sci. USA 1991, 88, 9330-9334.

(49) Marie-Claire, C.; Ruffet, E.; Beaumont, A.; Roques, B. P. The prosequence of thermolysin acts as an intramolecular chaperone when expressed in trans with the mature sequence in Escherichia coli. J. Mol. Biol. 1999, 285, 19111915.

(50) Vendrell, J.; Querol, E.; Avilés, F. X. Metallocarboxypeptidases and their protein inhibitors. Structure, function and biomedical properties. Biochim. Biophys. Acta 2000, 1477, 284-298.

(51) Seals, D. F.; Courtneidge, S. A. The ADAMs family of metalloproteases: multidomain proteins with multiple functions. Genes Dev. 2003, 17, 7-30.

(52) Avilés, F. X.; Vendrell, J.; Guasch, A.; Coll, M.; Huber, R. Advances in metallo-procarboxypeptidases. Emerging details on the inhibition mechanism and on the activation process. Eur. J. Biochem. 1993, 211, 381-389.

(53) San Segundo, B.; Martínez, M. C.; Vilanova, M.; Cuchillo, C. M.; Avilés, F. X. The severed activation segment of porcine pancreatic procarboxypeptidase $A$ is a powerful inhibitor of the active enzyme. Isolation and characterisation of the activation peptide. Biochim. Biophys. Acta 1982, 707, 74-80.

(54) Odintsov, S. G.; Sabala, I.; Marcyjaniak, M.; Bochtler, M. Latent LytM at 1.3Å resolution. J. Mol. Biol. 2004, 335, 775-785.

(55) Wong, E.; Maretzky, T.; Peleg, Y.; Blobel, C. P.; Sagi, I. The functional maturation of A Disintegrin and Metalloproteinase (ADAM) 9, 10, and 17 requires processing at a newly identified proprotein convertase (PC) cleavage site. J. Biol. Chem. 2015, 290, 12135-12146.

(56) Cao, J.; Drews, M.; Lee, H. M.; Conner, C.; Bahou, W. F.; Zucker, S. The propeptide domain of membrane type 1 matrix metalloproteinase is required for binding of tissue inhibitor of metalloproteinases and for activation of progelatinase A. J. Biol. Chem. 1998, 273, 34745-34752.

(57) Goulas, T.; Arolas, J. L.; Gomis-Rüth, F. X. Structure, function and latency regulation of a bacterial enterotoxin potentially derived from a mammalian adamalysin/ADAM xenolog. Proc. Natl. Acad. Sci. USA 2011, 108, 18561861.

(58) Arolas, J. L.; Goulas, T.; Pomerantsev, A. P.; Leppla, S. H.; Gomis-Rüth, F. X. Structural basis for latency and function of immune inhibitor A metallopeptidase, a modulator of the Bacillus anthracis secretome. Structure 2016, 24, 25-36. 
(59) Gao, X.; Wang, J.; Yu, D. Q.; Bian, F.; Xie, B. B.; Chen, X. L.; Zhou, B. C.; Lai, L. H.; Wang, Z. X.; Wu, J. W.et al. Structural basis for the autoprocessing of zinc metalloproteases in the thermolysin family. Proc. Natl. Acad. Sci. USA 2010, 107, 17569-17574.

(60) Kolattukudy, P. E.; Sirakova, T. D. In Handbook of Proteolytic Enzymes; Rawlings, N. D.;Salvesen, G., Eds.; Academic Press: Oxford, 2013; Vol. 1; p. 1270-1272.

(61) Gunja-Smith, Z.; Woessner Jr., J. F. Activation of cartilage stromelysin-1 at acid $\mathrm{pH}$ and its relation to enzyme $\mathrm{pH}$ optimum and osteoarthritis. Agents Actions 1993, 40, 228-231.

(62) Nagase, H. Activation mechanisms of matrix metalloproteinases. Biol. Chem. 1997, 378, 151-160.

(63) Woessner Jr., J. F.; Nagase, H. Matrix metalloproteinases and TIMPs (Protein Profile Series - Ed. P. Sheterline). Oxford University Press: New York, 2000.

(64) Bannikov, G. A.; Karelina, T. V.; Collier, I. E.; Marmer, B. L.; Goldberg, G. I. Substrate binding of gelatinase B induces its enzymatic activity in the presence of intact propeptide. J. Biol. Chem. 2002, 277, 16022-16027.

(65) Freise, C.; Erben, U.; Muche, M.; Farndale, R.; Zeitz, M.; Somasundaram, R.; Ruehl, M. The $\alpha 2$ chain of collagen type VI sequesters latent proforms of matrix-metalloproteinases and modulates their activation and activity. Matrix Biol. 2009, 28, 480-489.

(66) Fedarko, N. S.; Jain, A.; Karadag, A.; Fisher, L. W. Three small integrin binding ligand N-linked glycoproteins (SIBLINGs) bind and activate specific matrix metalloproteinases. FASEB J. 2004, 18, 734-736.

(67) Vater, C. A.; Mainardi, C. L.; Harris Jr., E. D. Activation in vitro of rheumatoid synovial collagenase from cell cultures. J. Clin. Invest. 1978, 62, 987-992.

(68) Arolas, J. L.; Gomis-Rüth, F. X. In Encyclopedia of Metalloproteins Uversky, V. N.;Kretsinger, R. H.;Permyakov, E. A., Eds.; Springer Verlag: Heidelberg (Germany), 2013; p. 2473-2479.

(69) Arolas, J. L.; Vendrell, J.; Aviles, F. X.; Fricker, L. D. Metallocarboxypeptidases: emerging drug targets in biomedicine. Curr. Pharm. Des. 2007, 13,349-366.

(70) Kalinina, E.; Biswas, R.; Berezniuk, I.; Hermoso, A.; Avilés, F. X.; Fricker, L. D. A novel subfamily of mouse cytosolic carboxypeptidases. FASEB J. 2007, 21, 836-850.

(71) Tanco, S.; Tort, O.; Demol, H.; Avilés, F. X.; Gevaert, K.; Van Damme, P.; Lorenzo, J. C-terminomics screen for natural substrates of cytosolic carboxypeptidase 1 reveals processing of acidic protein $\mathrm{C}$ termini. Mol. Cell. Proteomics 2015, 14, 177-190.

(72) Coll, M.; Guasch, A.; Aviles, F. X.; Huber, R. Three-dimensional structure of porcine procarboxypeptidase B: a structural basis of its inactivity. EMBO J. 1991, 10, 1-9.

(73) Otero, A.; Rodríguez de la Vega, M.; Tanco, S.; Lorenzo, J.; Avilés, F. X.; Reverter, D. The novel structure of a cytosolic M14 metallocarboxypeptidase (CCP) from Pseudomonas aeruginosa: a model for mammalian CCPs. FASEB J. 2012, 26, 3754-3764.

(74) García-Castellanos, R.; Bonet-Figueredo, R.; Pallarès, I.; Ventura, S.; Aviles, F. X.; Vendrell, J.; Gomis-Rüth, F. X. Detailed molecular comparison between the inhibition mode of A/B-type carboxypeptidases in the zymogen state and by the endogenous inhibitor latexin. Cell. Mol. Life Sci. 2005, 62, 1996-2014.

(75) Ollis, D. L.; Cheah, E.; Cygler, M.; Dijkstra, B.; Frolow, F.; Franken, S. M.; Harel, M.; Remington, S. J.; Silman, I.; Schrag, J.et al. The $\alpha / \beta$ hydrolase fold. Prot. Eng. 1992, 5, 197-211.

(76) Puente, X. S.; López-Otín, C. The PLEES-proteins - A family of structurally related enzymes widely distributed from bacteria to humans. Biochem. J. 1997, 332, 947-949.

(77) Madala, P. K.; Tyndall, J. D. A.; Nall, T.; Fairlie, D. P. Update 1 of: Proteases universally recognize beta strands In their active sites. Chem. Rev. 2010, 110, PR1-PR31.

(78) Valnickova, Z.; Thogersen, I. B.; Potempa, J.; Enghild, J. J. Thrombin-activable fibrinolysis inhibitor (TAFI) zymogen is an active carboxypeptidase. J. Biol. Chem. 2007, 282, 3066-3076.

(79) Plug, T.; Meijers, J. C. Structure-function relationships in thrombin-activatable fibrinolysis inhibitor. J. Thromb. Haemost. 2016, 14, 633-644.

(80) Sabala, I.; Jagielska, E.; Bardelang, P. T.; Czapinska, H.; Dahms, S. O.; Sharpe, J. A.; James, R.; Than, M. E.; Thomas, N. R.; Bochtler, M. Crystal structure of the antimicrobial peptidase lysostaphin from Staphylococcus simulans. FEBS J. 2014, 281, 4112-4122.

(81) Spencer, J.; Murphy, L. M.; Conners, R.; Sessions, R. B.; Gamblin, S. J. Crystal structure of the LasA virulence factor from Pseudomonas aeruginosa: substrate specificity and mechanism of M23 metallopeptidases. J. Mol. Biol. 2010, 396, 908-923.

(82) Marcyjaniak, M.; Odintsov, S. G.; Sabala, I.; Bochtler, M. Peptidoglycan amidase MepA is a LAS metallopeptidase. J. Biol. Chem. 2004, 279, 43982-43989.

(83) An, D. R.; Kim, H. S.; Kim, J.; Im, H. N.; Yoon, H. J.; Yoon, J. Y.; Jang, J. Y.; Hesek, D.; Lee, M.; Mobashery, S.et al. Structure of Csd3 from Helicobacter pylori, a cell shape-determining metallopeptidase. Acta Crystallogr. sect. D 2015, 71, 675-686.

(84) Wang, X.; Yang, X.; Yang, C.; Wu, Z.; Xu, H.; Shen, Y. Crystal structure of outer membrane protein NMB0315 from Neisseria meningitidis. PloS one 2011, 6, e26845.

(85) Ragumani, S.; Kumaran, D.; Burley, S. K.; Swaminathan, S. Crystal structure of a putative lysostaphin peptidase from Vibrio cholerae. Proteins 2008, 72, 1096-1103.

(86) Raulinaitis, V.; Tossavainen, H.; Aitio, O.; Juuti, J. T.; Hiramatsu, K.; Kontinen, V.; Permi, P. Identification and structural characterization of LytU, a unique peptidoglycan endopeptidase from the lysostaphin family. Sci. Rep. 2017, 7, 6020 .

(87) Tallant, C.; Marrero, A.; Gomis-Rüth, F. X. Matrix metalloproteinases: fold and function of their catalytic domains Biochim. Biophys. Acta-Mol. Cell Res. 2010, 1803, 20-28.

(88) Nagase, H.; Woessner Jr., J. F. Matrix metalloproteinases. J. Biol. Chem. 1999, 274, 21491-21494. 
(89) Wetmore, D. R.; Hardman, K. D. Roles of the propeptide and metal ions in the folding and stability of the catalytic domain of stromelysin (matrix metalloproteinase 3). Biochemistry 1996, 35, 6549-6558.

(90) Gomis-Rüth, F. X. A different look for $\mathrm{AB}_{5}$ toxins. Structure 2013, 21, 1909-1910.

(91) Cerdà-Costa, N.; Guevara, T.; Karim, A. Y.; Ksiazek, M.; Nguyen, K. A.; Arolas, J. L.; Potempa, J.; Gomis-Rüth, F. X. The structure of the catalytic domain of Tannerella forsythia karilysin reveals it is a bacterial xenologue of animal matrix metalloproteinases. Mol. Microbiol. 2011, 79, 119-132.

(92) Morgunova, E.; Tuuttila, A.; Bergmann, U.; Isupov, M.; Lindqvist, Y.; Schneider, G.; Tryggvason, K. Structure of human pro-matrix metalloproteinase-2 : Activation mechanism revealed. Science 1999, 284, 1667-1670.

(93) van Wart, H. E.; Birkedal-Hansen, H. The cysteine switch : a principle of regulation of metalloproteinase activity with potential applicability to the entire matrix metalloproteinase gene family. Proc. Natl. Acad. Sci. USA 1990, 87, 5578-5582.

(94) Springman, E. B.; Angleton, E. L.; Birkedal-Hansen, H.; Van Wart, H. E. Multiple modes of activation of latent human fibroblast collagenase : evidence for the role of a Cys73 active-site zinc complex in latency and a "cysteine switch" mechanism for activation. Proc. Natl. Acad. Sci. USA 1990, 87, 364-368.

(95) Rosenblum, G.; Meroueh, S.; Toth, M.; Fisher, J. F.; Fridman, R.; Mobashery, S.; Sagi, I. Molecular structures and dynamics of the stepwise activation mechanism of a matrix metalloproteinase zymogen: challenging the cysteine switch dogma. J. Am. Chem. Soc. 2007, 129, 13566-13574.

(96) Marchenko, N. D.; Marchenko, G. N.; Strongin, A. Y. Unconventional activation mechanisms of MMP-26, a human matrix metalloproteinase with a unique PHCGXXD cysteine-switch motif. J. Biol. Chem. 2002, 277, 18967-18972.

(97) Cha, J.; Pedersen, M. V.; Auld, D. S. Metal and pH dependence of heptapeptide catalysis by human matrilysin. Biochemistry 1996, 35, 15831-15838.

(98) Marino, G.; Funk, C. Matrix metalloproteinases in plants: a brief overview. Physiol. Plant. 2012, 145, 196-202.

(99) Marino-Puertas, L.; Goulas, T.; Gomis-Rüth, F. X. Matrix metalloproteinases outside vertebrates. Biochim. Biophys. Acta - Mol. Cell Res. 2017, 1864, 2026-2035.

(100) Hallmann, A.; Amon, P.; Godl, K.; Heitzer, M.; Sumper, M. Transcriptional activation by the sexual pheromone and wounding : a new gene family from Volvox encoding modular proteins with (hydroxy)proline-rich and metalloproteinase homology domains. Plant J. 2001, 26, 583-593.

(101) Shimizu, T.; Inoue, T.; Shiraishi, H. Cloning and characterization of novel extensin-like cDNAs that are expressed during late somatic cell phase in the green alga Volvox carteri. Gene 2002, 284, 179-187.

(102) Heitzer, M.; Hallmann, A. An extracellular matrix-localized metalloproteinase with an exceptional QEXXH metal binding site prefers copper for catalytic activity. J. Biol. Chem. 2002, 277, 28280-28286.

(103) Grams, F.; Huber, R.; Kress, L. F.; Moroder, L.; Bode, W. Activation of snake venom metalloproteinases by a cysteine switch-like mechanism. FEBS Lett. 1993, 335, 76-80.

(104) Leonard, J. D.; Lin, F.; Milla, M. E. Chaperone-like properties of the prodomain of TNFa-converting enzyme (TACE) and the functional role of its cysteine switch. Biochem. J. 2005, 387, 797-805.

(105) Loechel, F.; Overgaard, M. T.; Oxvig, C.; Albrechtsen, R.; Wewer, U. M. Regulation of human ADAM 12 protease by the prodomain. Evidence for a functional cysteine switch. J. Biol. Chem. 1999, 274, 13427-13433.

(106) Milla, M. E.; Gonzáles, P. E.; Leonard, J. D. The TACE zymogen: re-examining the role of the cysteine switch. Cel.l Biochem. Biophys. 2006, 44, 342-348.

(107) Guevara, T.; Yiallouros, I.; Kappelhoff, R.; Bissdorf, S.; Stöcker, W.; Gomis-Rüth, F. X. Proenzyme structure and activation of astacin metallopeptidase. J. Biol. Chem. 2010, 285, 13958-13965.

(108) Bode, W.; Gomis-Rüth, F. X.; Huber, R.; Zwilling, R.; Stöcker, W. Structure of astacin and implications for activation of astacins and zinc-ligation of collagenases. Nature 1992, 358, 164-167.

(109) Yiallouros, I.; Kappelhoff, R.; Schilling, O.; Wegmann, F.; Helms, M. W.; Auge, A.; Brachtendorf, G.; Berkhoff, E. G.; Beermann, B.; Hinz, H. J.et al. Activation mechanism of pro-astacin: role of the pro-peptide, tryptic and autoproteolytic cleavage and importance of precise amino-terminal processing. J. Mol. Biol. 2002, 324, 237-246.

(110) Huber, R.; Bode, W. Structural basis of the activation and action of trypsin. Acc. Chem. Res. 1978, 11, 114-122.

(111) Arolas, J. L.; Broder, C.; Jefferson, T.; Guevara, T.; Sterchi, E. E.; Bode, W.; Stöcker, W.; Becker-Pauly, C.; GomisRüth, F. X. Structural basis for the sheddase function of human meprin $\beta$ metalloproteinase at the plasma membrane. Proc. Natl. Acad. Sci. USA 2012, 109, 16131-16136.

(112) Xu, D.; Zhou, J.; Lou, X.; He, J.; Ran, T.; Wang, W. Myroilysin Is a new bacterial member of the M12A family of metzincin metallopeptidases and is activated by a cysteine switch mechanism. J. Biol. Chem. 2017, 292, 5195-5206.

(113) Sears, C. L. Enterotoxigenic Bacteroides fragilis: a rogue among symbiotes. Clin. Microbiol. Rev. 2009, 22, 349369.

(114) Shiryaev, S. A.; Aleshin, A. E.; Muranaka, N.; Kukreja, M.; Routenberg, D. A.; Remacle, A. G.; Liddington, R. C.; Cieplak, P.; Kozlov, I. A.; Strongin, A. Y. Structural and functional diversity of metalloproteinases encoded by the Bacteroides fragilis pathogenicity island. FEBS J. 2014, 281, 2487-2502.

(115) Goulas, T.; Gomis-Rüth, F. X. In Handbook of proteolytic enzymes.; 3rd ed.; Rawlings, N. D.;Salvesen, G. S., Eds.; Academic Press: Oxford, Great Britain, 2013; p. 887-891.

(116) Shiryaev, S. A.; Remacle, A. G.; Chernov, A. V.; Golubkov, V. S.; Motamedchaboki, K.; Muranaka, N.; Dambacher, C. M.; Capek, P.; Kukreja, M.; Kozlov, I. A.et al. Substrate cleavage profiling suggests a distinct function of Bacteroides fragilis metalloproteinases (fragilysin and metalloproteinase II) at the microbiome-inflammation-cancer interface. J. Biol. Chem. 2013, 288, 34956-34967.

(117) Edlund, T.; Sidén, I.; Boman, H. G. Evidence for two immune inhibitors from Bacillus thuringiensis interfering with the humoral defense system of saturniid pupae. Infect. Immun. 1976, 14, 934-941.

(118) Pflughoeft, K. J.; Swick, M. C.; Engler, D. A.; Yeo, H. J.; Koehler, T. M. Modulation of the Bacillus anthracis secretome by the immune inhibitor A1 protease. J. Bacteriol. 2014, 196, 424-435. 
(119) Adekoya, O. A.; Sylte, I. The thermolysin family (M4) of enzymes: therapeutic and biotechnological potential. Chem. Biol. Drug Des. 2009, 73, 7-16.

(120) Matthews, B. W.; Jansonius, J. N.; Colman, P. M.; Schoenborn, B. P.; Dupourque, D. Three-dimensional structure of thermolysin. Nature 1972, 238, 37-41.

(121) Demidyuk, I. V.; Gasanov, E. V.; Safina, D. R.; Kostrov, S. V. Structural organization of precursors of thermolysinlike proteinases. Protein J. 2008, 27, 343-354.

(122) Demidyuk, I. V.; Gromova, T. Y.; Polyakov, K. M.; Melik-Adamyan, W. R.; Kuranova, I. P.; Kostrov, S. V. Crystal structure of protealysin precursor: insights into propeptide function. J. Biol. Chem. 2010, 285, 2003-2013.

(123) Monod, M.; Paris, S.; Sanglard, D.; Jaton-Ogay, K.; Bille, J.; Latge, J. P. Isolation and characterization of a secreted metalloprotease of Aspergillus fumigatus. Infect. Immun. 1993, 61, 4099-4104.

(124) Fernández, D.; Russi, S.; Vendrell, J.; Monod, M.; Pallarés, I. A functional and structural study of the major metalloprotease secreted by the pathogenic fungus Aspergillus fumigatus. Acta Crystallogr. sect. D 2013, 69, 19461957.

(125) Pannifer, A. D.; Wong, T. Y.; Schwarzenbacher, R.; Renatus, M.; Petosa, C.; Bienkowska, J.; Lacy, D. B.; Collier, R. J.; Park, S.; Leppla, S. H.et al. Crystal structure of the anthrax lethal factor. Nature 2001, 414, 229-233.

(126) Göhler, A. K.; Staab, A.; Gabor, E.; Homann, K.; Klang, E.; Kosfeld, A.; Muus, J. E.; Wulftange, J. S.; Jahreis, K. Characterization of MtfA, a novel regulatory output signal protein of the glucose-phosphotransferase system in Escherichia coli K-12. J. Bacteriol. 2012, 194, 1024-1035.

(127) Xu, Q.; Göhler, A. K.; Kosfeld, A.; Carlton, D.; Chiu, H. J.; Klock, H. E.; Knuth, M. W.; Miller, M. D.; Elsliger, M. A.; Deacon, A. M.et al. The structure of Mlc titration factor A (MtfA/YeeI) reveals a prototypical zinc metallopeptidase related to anthrax lethal factor. J. Bacteriol. 2012, 194, 2987-2999.

(128) McAuley, K. E.; Jia-Xing, Y.; Dodson, E. J.; Lehmbeck, J.; Ostergaard, P. R.; Wilson, K. S. A quick solution : ab initio structure determination of a $19 \mathrm{kDa}$ metalloproteinase using ACORN. Acta Crystallogr. sect. D 2001, 57, $1571-1578$

(129) Hori, T.; Kumasaka, T.; Yamamoto, M.; Nonaka, N.; Tanaka, N.; Hashimoto, Y.; Ueki, U.; Takio, K. Structure of a new 'aspzincin' metalloendopeptidase from Grifola frondosa : implications for the catalytic mechanism and substrate specificity based on several different crystal forms. Acta Crystallogr. sect. D 2001, 57, 361-368.

(130) Laskowski Jr., M.; Kato, I. Protein inhibitors of proteinases. Annu. Rev. Biochem. 1980, 49, 593-626.

(131) Laskowski Jr., M.; Qasim, M. A. What can the structures of enzyme-inhibitor complexes tell us about the structures of enzyme substrate complexes? Biochim. Biophys. Acta 2000, 1477, 324-337.

(132) Bode, W.; Huber, R. Natural protein proteinase inhibitors and their interaction with proteinases. Eur. J. Biochem. 1992, 204, 433-451.

(133) Rigden, D. J.; Xu, Q.; Chang, Y.; Eberhardt, R. Y.; Finn, R. D.; Rawlings, N. D. The first structure in a family of peptidase inhibitors reveals an unusual Ig-like fold. F1000Res. 2013, 2, 154.

(134) Wong, E.; Cohen, T.; Romi, E.; Levin, M.; Peleg, Y.; Arad, U.; Yaron, A.; Milla, M. E.; Sagi, I. Harnessing the natural inhibitory domain to control TNF $\alpha$ converting enzyme (TACE) activity in vivo. Sci. Rep. 2016, 6, 35598.

(135) Moss, M. L.; Bomar, M.; Liu, Q.; Sage, H.; Dempsey, P.; Lenhart, P. M.; Gillispie, P. A.; Stoeck, A.; Wildeboer, D.; Bartsch, J. W.et al. The ADAM10 prodomain is a specific inhibitor of ADAM10 proteolytic activity and inhibits cellular shedding events. J. Biol. Chem. 2007, 282, 35712-35721.

(136) Gomis-Rüth, F. X. Third time lucky? Getting a grip on matrix metalloproteinases. J. Biol. Chem. 2017, 292, 17975 17976.

(137) Scannevin, R. H.; Alexander, R.; Mezzasalma Haarlander, T.; Burke, S. L.; Singer, M.; Hou, C.; Zhang, Y. M.; Maguire, D.; Spurlino, J.; Deckman, I.et al. Discovery of a highly selective chemical inhibitor of matrix metalloproteinase-9 (MMP-9) that allosterically inhibits zymogen activation. J. Biol. Chem. 2017, 292, 1796317974.

(138) Appleby, T. C.; Greenstein, A. E.; Hung, M.; Liclican, A.; Velasquez, M.; Villasenor, A. G.; Wang, R.; Wong, M. H.; Liu, X.; Papalia, G. A.et al. Biochemical characterization and structure determination of a potent, selective antibody inhibitor of human MMP9. J. Biol. Chem. 2017, 292, 6810-6820.

(139) Jozic, D.; Bourenkov, G.; Lim, N. H.; Visse, R.; Nagase, H.; Bode, W.; Maskos, K. X-ray structure of human proMMP-1: new insights into procollagenase activation and collagen binding. J. Biol. Chem. 2005, 280, 9578-9585.

(140) Morgunova, E.; Tuuttila, A.; Bergmann, U.; Tryggvason, K. Structural insight into the complex formation of latent matrix metalloproteinase 2 with tissue inhibitor of metalloproteinase 2. Proc. Natl. Acad. Sci. USA 2002, 99, 74147419.

(141) Becker, J. W.; A.I., M.; Rokosz, L. L.; Axel, M. G.; Burbaum, J. J.; Fitzgerald, P. M.; Cameron, P. M.; Esser, C. K.; Hagmann, W. K.; Hermes, J. D.et al. Stromelysin-1 : three-dimensional structure of the inhibited catalytic domain and of the C-truncated proenzyme. Prot. Sci. 1995, 4, 1966-1976.

(142) Prior, S. H.; Fulcher, Y. G.; Koppisetti, R. K.; Jurkevich, A.; Van Doren, S. R. Charge-triggered membrane insertion of matrix metalloproteinase-7, supporter of innate immunity and tumors. Structure 2015, 23, 2099-2110.

(143) Fulcher, Y. G.; Prior, S. H.; Masuko, S.; Li, L.; Pu, D.; Zhang, F.; Linhardt, R. J.; Van Doren, S. R. Glycan activation of a sheddase: electrostatic recognition between heparin and proMMP-7. Structure 2017, 25, 1100-1110.

(144) Elkins, P. A.; Ho, Y. S.; Smith, W. W.; Janson, C. A.; D'Alessio, K. J.; McQueney, M. S.; Cummings, M. D.; Romanic, A. M. Structure of the C-terminally truncated human ProMMP9, a gelatin-binding matrix metalloproteinase. Acta Crystallogr. sect. D 2002, 58, 1182-1192.

(145) López-Pelegrín, M.; Ksiazek, M.; Karim, A. Y.; Guevara, T.; Arolas, J. L.; Potempa, J.; Gomis-Rüth, F. X. A novel mechanism of latency in matrix metalloproteinases. J. Biol. Chem. 2015, 290, 4728-4740.

(146) Guasch, A.; Coll, M.; Avilés, F. X.; Huber, R. Three-dimensional structure of porcine pancreatic procarboxypeptidase A. A comparison of the A and B zymogens and their determinants for inhibition and activation. J. Mol. Biol. 1992, 224, 141-157. 
(147) Gomis-Rüth, F. X.; Gómez, M.; Bode, W.; Huber, R.; Avilés, F. X. The three-dimensional structure of the native ternary complex of bovine pancreatic procarboxypeptidase A with proproteinase $\mathrm{E}$ and chymotrypsinogen C. EMBO J. 1995, 14, 4387-4394.

(148) García-Sáez, I.; Reverter, D.; Vendrell, J.; Avilés, F. X.; Coll, M. The three-dimensional structure of human procarboxypeptidase A2. Deciphering the basis of the inhibition, activation and intrinsic activity of the zymogen. EMBO J. 1997, 16, 6906-6913.

(149) Estébanez-Perpiñá, E.; Bayes, A.; Vendrell, J.; Jongsma, M. A.; Bown, D. P.; Gatehouse, J. A.; Huber, R.; Bode, W.; Avilés, F. X.; Reverter, D. Crystal structure of a novel mid-gut procarboxypeptidase from the cotton pest Helicoverpa armigera. J. Mol. Biol. 2001, 313, 629-638.

(150) Fernández, D.; Boix, E.; Pallarés, I.; Avilés, F. X.; Vendrell, J. Analysis of a new crystal form of procarboxypeptidase B: further insights into the catalytic mechanism. Biopolymers 2010, 93, 178-185.

(151) Barbosa Pereira, P. J.; Segura-Martin, S.; Oliva, B.; Ferrer-Orta, C.; Avilés, F. X.; Coll, M.; Gomis-Rüth, F. X.; Vendrell, J. Human procarboxypeptidase B: three-dimensional structure and implications for thrombin-activatable fibrinolysis inhibitor (TAFI). J. Mol. Biol. 2002, 321, 537-547.

(152) Marx, P. F.; Brondijk, T. H.; Plug, T.; Romijn, R. A.; Hemrika, W.; Meijers, J. C.; Huizinga, E. G. Crystal structures of TAFI elucidate the inactivation mechanism of activated TAFI: a novel mechanism for enzyme autoregulation. Blood 2008, 112, 2803-2809.

(153) Brink, M.; Dahlen, A.; Olsson, T.; Polla, M.; Svensson, T. Design and synthesis of conformationally restricted inhibitors of active thrombin activatable fibrinolysis inhibitor (TAFIa). Bioorg. Med. Chem. 2014, 22, 2261-2268.

(154) Zhou, X.; Weeks, S. D.; Ameloot, P.; Callewaert, N.; Strelkov, S. V.; Declerck, P. J. Elucidation of the molecular mechanisms of two nanobodies that inhibit thrombin-activatable fibrinolysis inhibitor activation and activated thrombin-activatable fibrinolysis inhibitor activity. J. Thromb. Haemost. 2016, 14, 1629-1638.

(155) Anand, K.; Pallarés, I.; Valnickova, Z.; Christensen, T.; Vendrell, J.; Wendt, K. U.; Schreuder, H. A.; Enghild, J. J.; Avilés, F. X. The crystal structure of thrombin-activable fibrinolysis inhibitor (TAFI) provides the structural basis for its intrinsic activity and the short half-life of TAFIa. J. Biol. Chem. 2008, 283, 29416-29423.

\section{TABLE OF CONTENTS GRAPHICS}

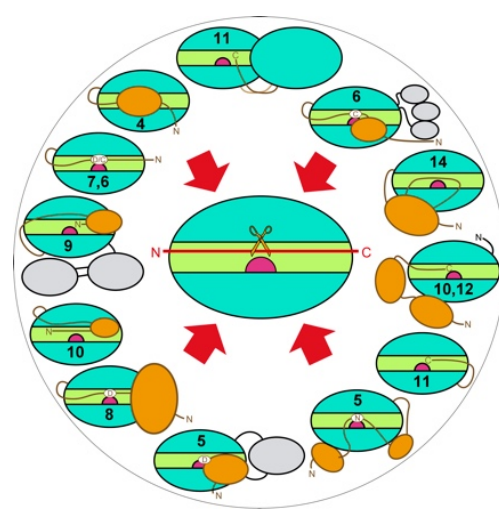

In the center, mature metallopeptidases (in turquoise) cleave (scissors) protein and peptide substrates (in red) bound to an active-site cleft (in light green) containing a catalytic zinc ion (in magenta) in a particular N-to-C orientation. Given the irreversibility of this cleavage, metallopeptidases must be kept latent until reaching their physiological site of action. Several latency mechanisms have been documented through structural studies, represented by the zymogens surrounding the mature enzyme. Zymogen pro-segments are depicted as orange ellipses and other ancillary domains are in gray. Particular pro-segment residues binding the catalytic zinc are shown in one-letter code within white ellipses, $\mathrm{N}$ - or C-termini of the zymogens are labeled in brown. Numbers refer to the corresponding sections in the text. 